\title{
Calcineurin Activity Is Increased in Charcot-Marie-Tooth 1B Demyelinating Neuropathy
}

\author{
Mariapaola Sidoli, ${ }^{1,2,4}$ Chelsey B. Reed, ${ }^{1,3}$ Cristina Scapin, ${ }^{5}{ }^{\circledR}$ Pablo Paez, ${ }^{1,2}{ }^{\circ}$ Douglas R. Cavener, ${ }^{6}$ \\ Randal J. Kaufman, ${ }^{7}{ }^{\oplus}$ Maurizio D’Antonio, ${ }^{5}{ }^{\circledR}$ M. Laura Feltri, ${ }^{1,2,3}$ and ${ }^{\circledR}$ Lawrence Wrabetz ${ }^{1,2,3}$ \\ ${ }^{1}$ Hunter James Kelly Research Institute, Jacobs School of Medicine and Biomedical Sciences, University at Buffalo, Buffalo, New York 14203, \\ ${ }^{2}$ Department of Biochemistry, Jacobs School of Medicine and Biomedical Sciences, University at Buffalo, Buffalo, New York 14203, ${ }^{3}$ Department of \\ Neurology, Jacobs School of Medicine and Biomedical Sciences, University at Buffalo, Buffalo, New York 14203, ${ }^{4}$ Department of Developmental \\ Biology, School of Medicine, Stanford University, Stanford, California 94305, ${ }^{5}$ Division of Genetics and Cell Biology, San Raffaele Scientific Institute, \\ DIBIT, Milan 20132, Italy, ${ }^{6}$ Department of Biology, Center for Cellular Dynamics, Pennsylvania State University, University Park, Pennsylvania \\ 16802, and ${ }^{7}$ Degenerative Diseases Program, Sanford Burnham Prebys Medical Discovery Institute, La Jolla, California 92037
}

Schwann cells produce a considerable amount of lipids and proteins to form myelin in the PNS. For this reason, the quality control of myelin proteins is crucial to ensure proper myelin synthesis. Deletion of serine 63 from P0 (P0S63del) protein in myelin forming Schwann cells causes Charcot-Marie-Tooth type 1B neuropathy in humans and mice. Misfolded P0S63del accumulates in the ER of Schwann cells where it elicits the unfolded protein response (UPR). PERK is the UPR transducer that attenuates global translation and reduces ER stress by phosphorylating the translation initiation factor eIF2alpha. Paradoxically, Perk ablation in P0S63del Schwann cells (S63del/Perk ${ }^{S C K O}$ ) reduced the level of P-eIF2alpha, leaving UPR markers upregulated, yet unexpectedly improved S63del myelin defects in vivo. We therefore investigated the hypothesis that PERK may interfere with signals outside of the UPR and specifically with calcineurin/NFATc4 pro-myelinating pathway. Using mouse genetics including females and males in our experimental setting, we show that PERK and calcineurin interact in P0S63del nerves and that calcineurin activity and NFATc4 nuclear localization are increased in S63del Schwann cells, without altering EGR2/KR0X20 expression. Moreover, genetic manipulation of the calcineurin subunits appears to be either protective or toxic in S63del in a context-dependent manner, suggesting that Schwann cells are highly sensitive to alterations of calcineurin activity.

Key words: demyelination; Charcot-Marie-Tooth; myelin; PERK; calcineurin; Schwann cells

Significance Statement

Our work shows a novel activity and function for calcineurin in Schwann cells in the context of ER stress. Schwann cells expressing the S63del mutation in P0 protein induce the unfolded protein response and upregulate calcineurin activity. Calcineurin interacts with the ER stress transducer PERK, but the relationship between the UPR and calcineurin in Schwann cells is unclear. Here we propose a protective role for calcineurin in S63del neuropathy, although Schwann cells appear to be very sensitive to its regulation. The paper uncovers a new important role for calcineurin in a demyelinating diseases.

Received Sep. 12, 2020; revised Mar. 8, 2021; accepted Mar. 17, 2021.

Author contributions: M.S., M.D., M.L.F., and L.W. designed experiment; M.S., C.B.R., C.S., and P.P. performed experiment; M.S., P.P., M.L.F., and L.W. analyzed data; P.P., D.R.C., and R.J.K. contributed reagents; M.S., M.D., M.L.F., and L.W. wrote the paper.

This work was supported by National Institutes of Health Grants R01 and R56NS096104 to L.W. and Grant NS045630 to M.L.F.; Telethon Italy GGP071100 to L.W.; GGP08821 to M.L.F.; GGP14147 to M.D.; European Community FP7/2007-1013 under Grant Agreement HEALTH-F2-2008-201535 to L.W. and M.L.F.; CharcotMarie-Tooth Association to L.W.; and Italian Ministry of Health GR-2011-02346791 to M.D. R.J.K. was supported in part by National Institutes of Health Grants CA198103, DK113171, and AG062190. M.S. was supported by NMSS Fellowship FG-1807-31636. We thank Ed Hurley for the processing of sciatic nerves for semithin and electron microscopy, Virginia Lee (University of Pennsylvania) for anti-MBP antibodies, and Dies Mejer (University of Edinburgh) for anti-EGR2 antibodies.

The authors declare no competing financial interests.

Correspondence should be addressed to Mariapaola Sidoli at mpsidoli@stanford.edu or M. Laura Feltri at mlfeltri@buffalo.edu.

https://doi.org/10.1523/JNEUROSCI.2384-20.2021

Copyright $\odot 2021$ the authors

\section{Introduction}

Myelin is the insulating membrane that surrounds axons to provide trophic support and to promote the fast transmission of electrical impulses (Sherman and Brophy, 2005). Schwann cells produce myelin in the PNS, a process that demands large synthesis of proteins and lipids and requires an efficient protein quality control system to cope with such burden (D'Antonio et al., 2009; Lin and Popko, 2009; Lin and Stone, 2020). In humans and mice, deletion of serine 63 from Myelin Protein Zero (P0S63del) impairs myelination in peripheral nerves, causing CharcotMarie-Tooth1B-S63del (CMT1B-S63del), a debilitating demyelinating neuropathy characterized by reduction of nerve conduction velocity and motor impairment (Kulkens et al., 1993; Wrabetz et al., 2006; Miller et al., 2012). 
A
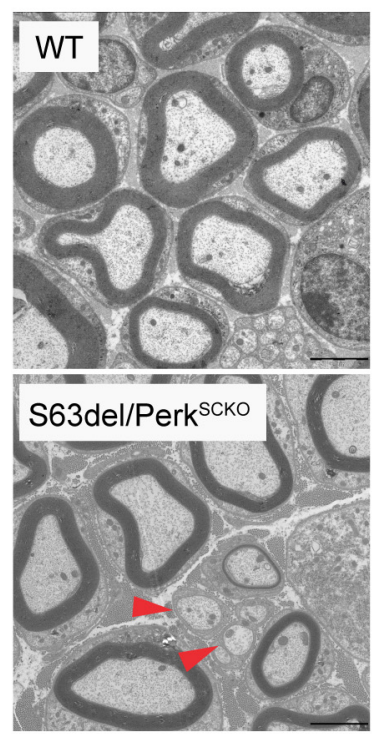

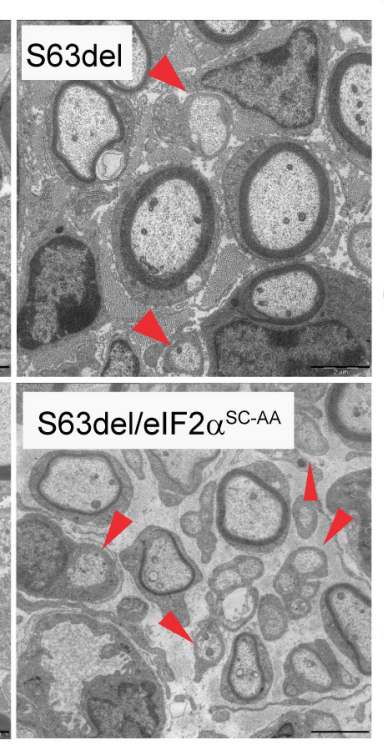

B

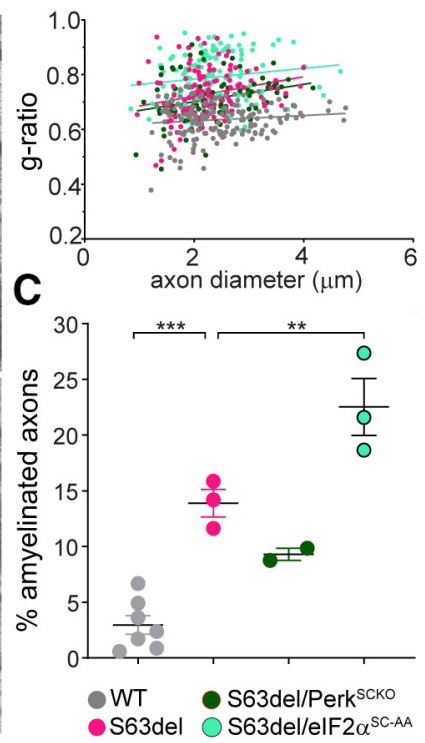

Figure 1. Loss of phosphorylated elF2alpha is detrimental for S63del Schwann cells. A, EM sections of sciatic nerves dissected between P21 and P28 of the following genotypes: A/A;fTg and WT (WT), A/A;fTg;S63del and S63del (S63del), A/A;fTg;

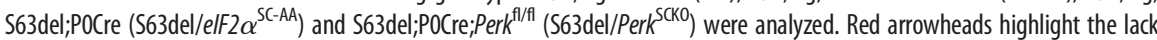
of myelin in small- and medium-caliber axons in AA//fTg//S63del, S63del/elF2 $\alpha^{\text {SCAA }}$, and S63del//Perk ${ }^{\text {SCKO }}$. Scale bar, $2 \mu \mathrm{m}$. $\boldsymbol{B}$, EM sections were quantified for $\mathrm{g}$-ratio plotted as function of axon diameter and $(\boldsymbol{C}) \%$ of amyelinated axons (red arrowheads) using 150-170 axon from 3 or 4 animals, except for $563 \mathrm{del}^{\prime} / \mathrm{Perk}^{\mathrm{SCKO}}$, for which only 2 animals were quantified. Error bars indicate SEM. ${ }^{* *} p<0.01 ;{ }^{* * *} p<0.001$; one-way ANOVA with Bonferroni multiple comparison test.

P0S63del generates a misfolded protein that accumulates in the ER of Schwann cells and triggers the unfolded protein response (UPR) (Wrabetz et al., 2006; Pennuto et al., 2008; D’Antonio et al., 2013). Among the strategies adopted to restore protein homeostasis, the UPR reduces translation by activating protein kinase RNA-like endoplasmic reticulum kinase (PERK) via its dimerization and autophosphorylation (Harding et al., 2000b, 2001; P. Zhang et al., 2002). P-PERK phosphorylates and blocks the activity of the eukaryotic translation initiation factor eIF2alpha, and thereby, transiently attenuating protein synthesis to limit the accumulation of client proteins in the ER (Harding et al., 2000a). PERK and eIF2alpha are remarkably active in S63del nerves, suggesting that Schwann cells attempt to alleviate the ER stress by reducing translation (D'Antonio et al., 2013; Musner et al., 2016). To prevent an excessive translational shut down, the growth arrest and DNA damage-inducible protein (GADD34)-PP1 holophosphatase dephosphorylates eIF2alpha to restart translation (Novoa et al., 2001).

In S63del nerves, increasing phosphorylation of eIF2alpha through genetic and pharmacological impairment of GADD34 activity nearly rescues S63del neuropathy, suggesting that the PERK-eIF2alpha arm of the UPR is adaptive for the neuropathy (D’Antonio et al., 2013; Das et al., 2015). Paradoxically, reducing eIF2alpha phosphorylation by targeted deletion of Perk in Schwann cells (S63del/Perk ${ }^{\mathrm{SCKO}}$ mice) also ameliorates myelin morphology in S63del nerves, although P0 accumulation in the ER remains high (Sidoli et al., 2016). Given these data, we hypothesized that PERK may have an eIF2alpha-independent effect.

Work done in Xenopus and mammalian cells has demonstrated that P-PERK can regulate the activity of the phosphatase calcineurin (Bollo et al., 2010; R. Wang et al., 2013; Liu et al., 2014; Chen et al., 2016). Previous reports suggest that calcineurin promotes myelin formation in both the PNS and the CNS (Kao et al., 2009; Weider et al., 2018). In immature Schwann cells, activation of calcineurin induces the expression of the promyelinating transcription factor Early Growth Response 2 (EGR2/ KROX20), thus representing an ideal candidate to be disrupted by P-PERK in a demyelinating neuropathy with an active UPR (Kao et al., 2009). However, our recent data have demonstrated that selective deletion of calcineurin in myelinating Schwann cells has no effect on KROX20 expression or myelin production, but rather limits myelin clearance after injury (Reed et al., 2020). We thus explored the hypothesis that P-PERK interacts and modulates calcineurin activity in S63del Schwann cells, thus contributing to the demyelinating neuropathy. We show here that, indeed, PERK and calcineurin interact in S63del sciatic nerves, and that calcineurin activity is upregulated in mutant nerves compared with WT control. In vivo, loss of calcineurin activity in S63del Schwann cells further impairs myelination and causes early axonal degeneration pointing to a novel protective role for calcineurin in Schwann cells in the context of ER stress. Moreover, the detrimental effect of calcineurin loss of function in S63del nerves is reversed by simultaneous deletion of calcineurin and Perk. This work suggests a novel and tightly regulated function for calcineurin in CMT1b-S63del neuropathy and prompts further work to understand calcineurin action in Schwann cell myelination during disease or injury.

\section{Materials and Methods}

Mice. All the animals involved in this work were treated according to the experimental protocols approved by the Department of Laboratory and Animal Resource core facility at Roswell Roswell Park Cancer Institute, by University at Buffalo Institutional Animal Care and Use Committees, and by San Raffaele Scientific Institute Animal Care and Use Committee. The experiments included both female and male mice.

P0S63del transgenic mouse and S63del/Perk ${ }^{\mathrm{SCKO}}$ mouse model were previously described (Wrabetz et al., 2000, 2006; P. Zhang et al., 2002; Sidoli et al., 2016). eIF2alpha ${ }^{\mathrm{A} / \mathrm{A}}$ and eIF2alpha $(f / \mathrm{Tg})$ were characterized by Back et al. (2009). To generate Schwann cell-specific loss of function of calcineurin, we crossed (P0Cre) mice (Feltri et al., 1999) with mice carrying a Calcineurin regulatory subunit $B(\mathrm{CnB})$ floxed conditional allele (B6;129-Ppp3r1 $1^{\text {tm2Grc } / J) ~(N e i l s o n ~ e t ~ a l ., ~ 2004) . ~ T h e ~ k n o c k o u t ~ a l l e l e ~}$ for the catalytic subunit $A$ isoform $\alpha$ of Calcineurin (CnAalpha) (B6;129-Ppp3ca ${ }^{t m 1 J s e / J}$ ) was characterized by B. W. Zhang et al. (1996). Mice were maintained as $\mathrm{C} 57 \mathrm{BL} / 6 \mathrm{~N}$ and further crossed in S63del background to obtain $\mathrm{S} 63 \mathrm{del} / \mathrm{CnB} \mathrm{B}^{\mathrm{SCKO}}$ and $\mathrm{S} 63 \mathrm{del} / \mathrm{CnA}^{-1-}$. In Figure $1 A$, we used A/A;fTG;S63del in FVB/C57BL6 mixed background. The experimental crosses were designed to obtain genotypes of interest and controls within littermates, to control for possible biological variability because of genetic background.

Morphology. P28, P21, and P10 mutant and control mice from same littermates were sacrificed and sciatic nerves collected. Semithin section and electron microscopy (EM) were performed as previously described (Quattrini et al., 1996). Images for semithin were acquired with a $100 \times$ objective on a Leica DM 6000 microscope while for EM we used a FEI Tecnai G2 Spirit bio twin electron microscope. The g-ratio and 
amyelinated axon count were analyzed as previously described (Sidoli et al., 2016).

Western blotting (WB). Sciatic nerves from P28 mutant and control mice were frozen, pulverized, and lysed in RIPA buffer (Tris $\mathrm{HCl} 50 \mathrm{~mm}$, pH 8.0, NaCl $150 \mathrm{~mm}, \mathrm{NP}-40$ 1\%, sodium deoxycholate 0.5\%, SDS 0.1\%) plus $1 \mathrm{~mm} \mathrm{Na}_{3} \mathrm{VO}_{4}, 1 \%$ phosphatase inhibitor cocktail C2 and C3, and $1 \%$ Protease inhibitor cocktail (Sigma Millipore). Samples were mixed with loading dye $6 \times(360 \mathrm{~mm}$ Tris- $\mathrm{HCl}, \mathrm{pH} 6.8,30 \%$ glycerol, $10 \%$ SDS, $0.012 \%$ bromophenol blue, $0.6 \mathrm{~m} \mathrm{DTT}$ ), boiled for $5 \mathrm{~min}$, and centrifuged at room temperature. Protein sizes were resolved in bis Tris gel (Sigma Millipore) and MOP SDS running buffer (Thermo Fisher Scientific) and blotted on PVDF membrane (GE Healthcare, Odyssey detection system). For cellular fractionation, nerve powder was mixed with cytoplasmic lysis buffer (HEPES $10 \mathrm{~mm}, \mathrm{pH} 6.8$, EDTA 5 m , digitonin $0.01 \%$ ), incubated for $10 \mathrm{~min}$ at $4^{\circ} \mathrm{C}$, and centrifuged at $1000 \times g$ at $4^{\circ} \mathrm{C}$ for $10 \mathrm{~min}$. The supernatant was saved as the cytoplasmic fraction, and the pellet was resuspended with membrane lysis buffer (HEPES 10 mm, pH 7.4, EDTA $5 \mathrm{~mm}$, Triton X-100 0.5\%) and rotated for $30 \mathrm{~min}$ at $4^{\circ} \mathrm{C}$. Samples were then centrifuged at $5000 \times g$ at $4^{\circ} \mathrm{C}$ for $10 \mathrm{~min}$. The supernatant was collected as the membrane fraction but not used. The pellet was then resuspended with nuclear lysis buffer (HEPES $10 \mathrm{~mm}$, pH 7.4, EDTA $5 \mathrm{~mm}$, Tween-20 $1 \%$, DOC $0.5 \%$ ), incubated at $4^{\circ} \mathrm{C}$ for $10 \mathrm{~min}$, and centrifuged at $6800 \times g$ at $4^{\circ} \mathrm{C}$ for $10 \mathrm{~min}$. Fractions were resolved on an SDS-polyacrylamide gel.

Immunoprecipitation. At least four nerves for each genotype were pooled together and lysed with CHAPS buffer (HEPES $40 \mathrm{~mm}, \mathrm{pH} 7.5$, $\mathrm{NaCl} 120 \mathrm{~mm}$, EDTA $1 \mathrm{~mm}$, sodium pyrophosphate decahydreate $1 \mathrm{~mm}$, $\beta$-glycerophosphate $1 \mathrm{~mm}$, sodium fluoride $5 \mathrm{~mm}$, CHAPS $0.3 \%$, Thermo Fisher Scientific). Lysis was performed on ice with previously frozen cold tubes and pestles. After homogenization, the samples were resuspended with $23 \mathrm{G}$ needle and syringe. Tubes were left on ice for $10 \mathrm{~min}$ and then cleared by centrifugation at $10,000 \times g$ at $4^{\circ} \mathrm{C}$ for $20 \mathrm{~min}$. Bead preclearing was done by adding Protein A/G agarose (Santa Cruz Biotechnology) to the lysates for $1 \mathrm{~h}$ at $4^{\circ} \mathrm{C}$ with end-overend rotation. After discarding the beads, the lysates were incubated with primary antibody overnight at $4^{\circ} \mathrm{C}$. Beads were added to the antibodylysate sample at $4^{\circ} \mathrm{C}$ for $3 \mathrm{~h}$ and then washed 3 times with lysis buffer plus one time with PBS1X. All solutions were removed with $27 \mathrm{G}$ needle and syringe. Immunoprecipitation samples were mixed with $2 \times$ loading dye (DTT $1 \mathrm{~m}$, SDS 10\%, Tris-Cl $1 \mathrm{~m}, \mathrm{pH} 6.8$, bromophenol blue $1 \%$ ), boiled at $95^{\circ} \mathrm{C}$ for $10 \mathrm{~min}$, and loaded on a SDS page gel for CnA-Perk (P-Thr198) coimmunoprecipitation.

Antibodies. $\alpha$-Tubulin (600-939, Novus Biologicals, 1:2000 for WB), GAPDH (G9545, Sigma Millipore, 1:5000 for WB), H2B (ab18977, Abcam, 1:1000 for WB) P-eIF2alpha (3398, Cell Signaling Technology, 1:500 for WB), P-PERK Thr198 (3179, Cell Signaling Technology, 1:500 for WB), Pan-calcineurin A (2614, Cell Signaling Technology, 1:50 for immunoprecipitation/immunofluorescence and 1:1000 for WB), calcineurin B (CnB, 07-069, Millipore, 1:1000 WB), calmodulin (CaM, 4830, Cell Signaling Technology, 1:1000 WB), Tuj1 (801202, BioLegend, 1:500 for immunofluorescence), NFATc4 (2183, Cell Signaling Technology, 1:1000 for WB; and PA1-021, Thermo Fisher Scientific, 1:100 for immunofluorescence), MBP was from Virginia Lee at University of Pennsylvania 1:4 for immunofluorescence, and Egr2 was from Mejer in University of Edinburgh, 1:6000 for immunofluorescence. Tubulin, calcineurin A (CnA), and $\mathrm{CnB}$ were detected with the Odyssey CLx infrared imaging system IRDye 800 anti-rabbit (Li-Cor, 1:10,000). All the other proteins were visualized using HRP-conjugated secondary antibodies against rabbit (DAKO, 1:5000). The densitometry was performed with ImageJ-64 software.

Calcineurin assay. The enzymatic activity of calcineurin was measured using the calcineurin cellular activity assay kit from Enzo Life Sciences (BML-AK816-0001) and following the manufacturer's instruction. In brief, three to five pair of nerves from WT, S63del, and S63del/ Perk $^{\text {SCKO }}$ were pulled together to generate one lysate each genotype. Nerves were crashed with frozen pestles in frozen tubes with lysis buffer (BML-KI135-0040) and mixed with 23 G needle plus syringe. Samples were ultracentrifuged for $45 \mathrm{~min}, 65,000 \mathrm{rpm}$ at $4^{\circ} \mathrm{C}$. Supernatant was collected and desalted using desalting column resin (BML-KI100). Samples were centrifuged at $800 \times g$ for $3 \mathrm{~min}$. Calcineurin activity was measured by subtracting free phosphate background per the manufacturer's instruction. The EGTA control was measured by adding $20 \mathrm{~mm}$ of EGTA to S63del nerve lysate.

Immunofluorescence. Mutant and control nerves and DRGs were dissected from P28 mice, fixed in 4\% ice cold PFA for $30 \mathrm{~min}$, and cryo-preserved in sucrose $20 \%$ overnight. Nerves were then embedded in OCT (Miles) before freezing them in liquid nitrogen for cryostat sectioning. Alternatively, nerves were teased on 3\% 3-triethoxysilylpropylamine-coated slides (Sigma Millipore). Longitudinal sections of $10 \mu \mathrm{m}$ thickness were postfixed in 4\% PFA for $15 \mathrm{~min}$ and permeabilized in acetone for $5 \mathrm{~min}$. Blocking was achieved in $10 \%$ FCS, $0.2 \%$ Triton X-100 in PBS $1 \times$ (for Egr2) or $5 \%$ BSA, $1 \%$ NGS, $0.5 \%$ Triton X-100 in PBS $1 \times$ (for NFATc4, $\mathrm{MBP}$, and CnA immunofluorescence). Washing was performed with TBS $1 \times$, and slides were incubated for $1 \mathrm{~h}$ at room temperature with Jackson Alexa-488 secondary antibodies against rabbit and rat, or Alexa-594 against the mouse IgG sub2a (1:500). Nuclei were highlighted with DAPI.

TaqMan $q P C R$. RNA purification, cDNA production, and TaqMan PCR analyses from P10 and P28 sciatic nerves and cDNA production were performed as previously described (Sidoli et al., 2016). The PCR for the target and reference genes were performed in separate test tubes with Assays on Demand (Applied Biosystems Instruments): Egr2/Krox20 (Mm00456650_ m1), Oct6/Pouf3 (Mm00843534_s1), Sox2 (Mm03053810_s1), Sox10 (Mm00569909_m1), NFATc4 (Mm00452375_m1), c-Jun, Yy1 (Mm00456392_m1). Normalization was performed using rRNA 18s, Hs99999901_s1. Littermates were analyzed and every genotype was compared with the WT of the same cohort.

$D R G$ explants. DRG explants were isolated from E13.5 mouse embryos from WT, S63del, and S63delH litter for calcium imaging and WT, CnAalpha ${ }^{-1-}$, S63del, and S63del/CnAalpha ${ }^{-1-}$ for in vitro myelination assay. DRGs were cultured as described by Taveggia et al. (2005). In brief, DRGs were cultured on collagen-coated coverslip (Cultrex Trevigen, 3440-100-01) with $50 \mu \mathrm{g} / \mathrm{ml}$ final concentration of collagen. Myelination was induced by treating DRGs with $50 \mu \mathrm{g} / \mathrm{ml}$ of ascorbic acid (AA, Sigma Millipore) for 5 or $12 \mathrm{~d}$, after which the number of myelinated internodes were quantified.

Calcium imaging. Calcium imaging was performed as previously shown by Paez et al. (2007). Briefly, nonmyelinating and myelinating ( $5 \mathrm{~d}$ of AA) DRG explants were washed in serum and phenol red-free DMEM containing a final concentration of $4 \mu \mathrm{M}$ fura-2 AM (TefLabs) and $0.08 \%$ Pluronic F127 (Invitrogen) to load dye into the cells. Cells were then incubated for $25 \mathrm{~min}$ at $37^{\circ} \mathrm{C}, 5 \% \mathrm{CO}_{2}$, then washed $4 \times$ in DMEM, and stored in DMEM for 10 min before being imaged. Calcium flux was induced by treating DRGs with ATP $(100 \mathrm{~mm})$. Time lapse images were obtained by measuring fura- 2 at $2 \mathrm{~s}$ intervals for a total of $4 \mathrm{~min}$ at low excitation light to minimize bleaching. Each frame represents a single section of fura- 2 , and increased in calcium concentration is indicated by warmer color (red). Resting and stimulated $\mathrm{Ca}^{2+}$ levels were measured in $\mathrm{Mg}^{2+}$ and serum-free HBSS containing $2 \mathrm{mM} \mathrm{Ca}^{2+}$, or $\mathrm{Mg}^{2+}$ and $\mathrm{Ca}^{2+}$ free HBSS (-Ca). $\mathrm{Ca}^{2+}$ levels were measured on individual cells, and the results were pooled from three separate experiments for each condition. The fluorescence of fura-2 was excited alternating 340 and $380 \mathrm{~nm}$ wavelengths by means of a high-speed wavelength switching device ( $\lambda$ DG4; Sutter Instruments). A spinning disk confocal inverted microscope (Olympus, IX83-DSU), equipped with a CCD camera (Hamamatsu ORCA-R2), measured the fluorescence, and time lapse was acquired with a $20 \times$ objective. Image analysis software (MetaFluor, Molecular Devices) allowed for the selection of several "regions of interest" within the field from which measurements were taken.

Statistical analysis. All statistical analysis was conducted using GraphPad Prism 6.01. To determine the significance between genotypes, Student's $t$ test or one-way and two-way ANOVA were used. $p \leq 0.05$ was considered statistically significant. Graphical data are represented as mean \pm SD $(\mathrm{SE})$ or SEM.

\section{Results}

\section{Loss of eIF2alpha phosphorylation is deleterious in S63del Schwann cells}

The phosphorylation of eIF2alpha represents a protective response in cells undergoing chronic ER stress, including S63del 
A

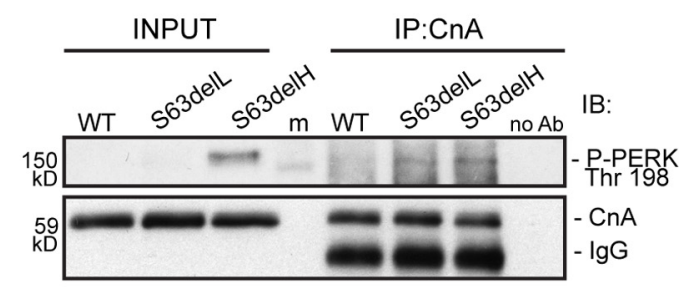

C WT adult DRG

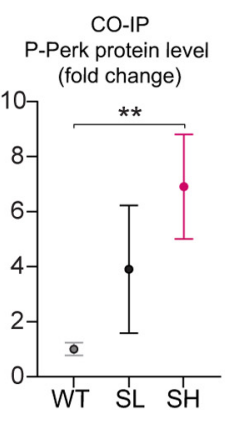

B
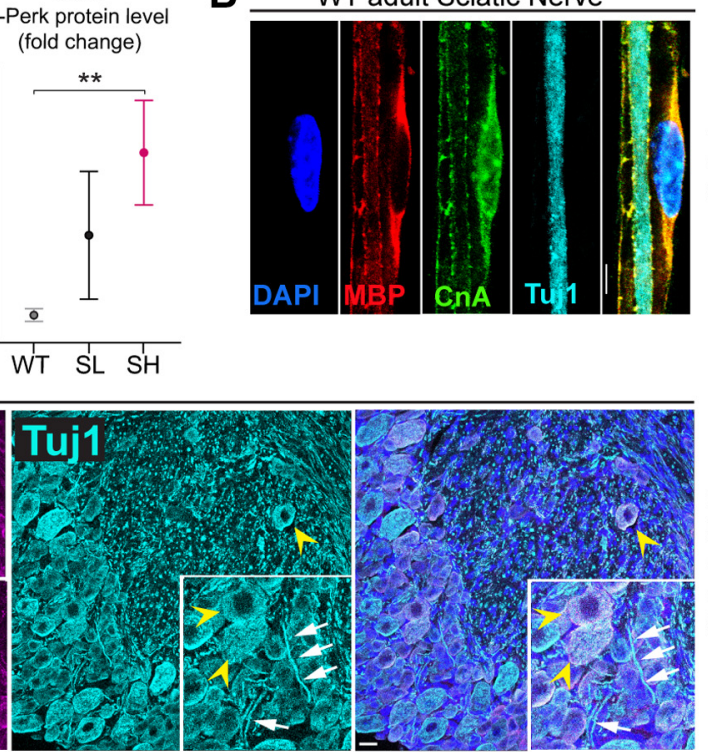
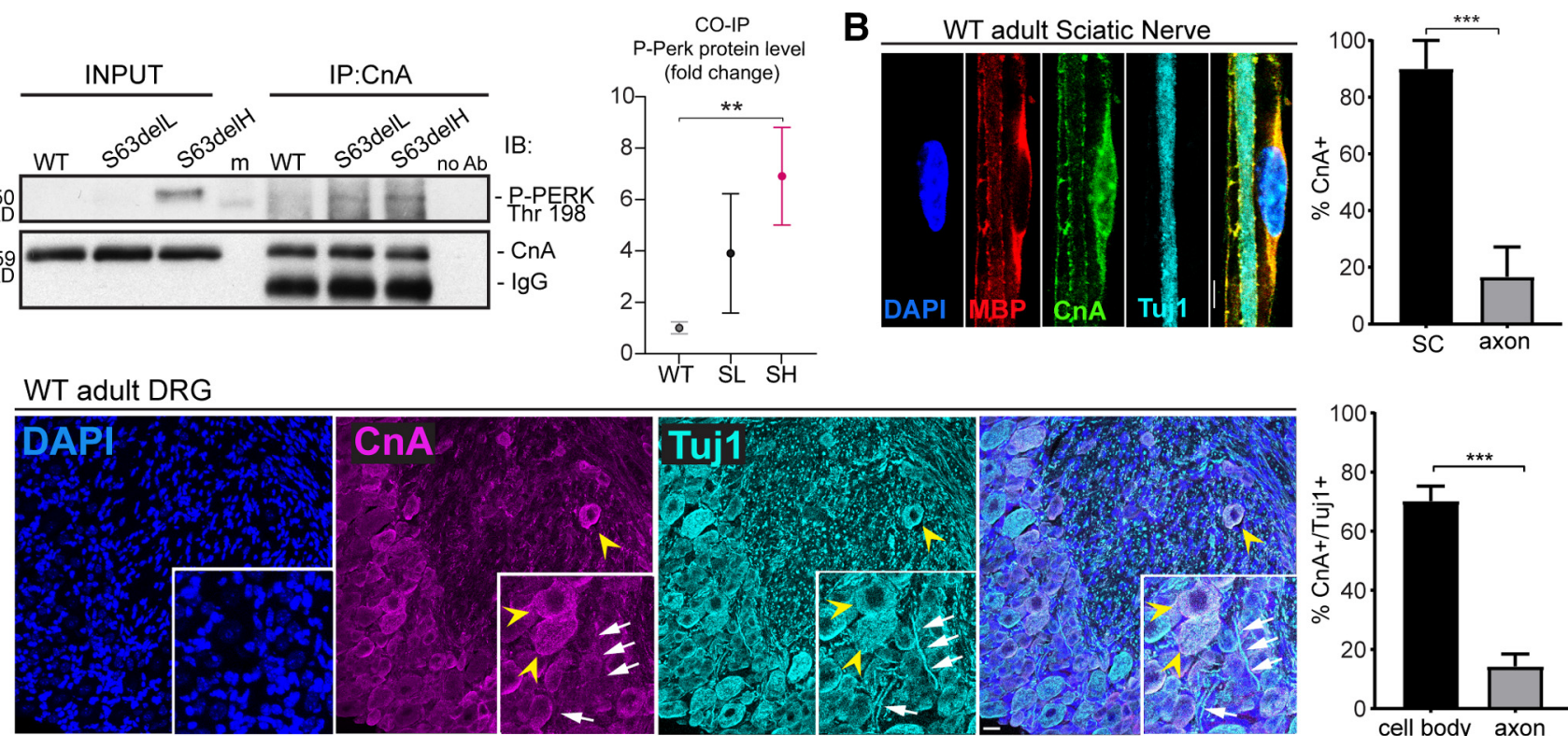

Figure 2. P-PERK binds calcineurin in S63del sciatic nerve. $A$, Calcineurin immunoprecipitation was performed on P28 sciatic nerve from WT, S63delL, and S63delH mice. WB reveals calcineurin (CnA) and P-PERK coimmunoprecipitating (P-PERK Thr198). IgG heavy chain from the beads was detected in the immunoprecipitation from WT, S63del-L, and S63del-H sciatic nerves right below the $\mathrm{CnA}$ band. The lgG are absent in the control with no antibody added to the lysate (no Ab), indicating the specificity of the beads-antibody binding. Between the input and the immunoprecipitation, there is a band that corresponds to cross-reactivity with the protein marker $(\mathrm{m})$. Graph represents the quantification of the coimmunopreciptated P-PERK normalized with CnA. Error bars indicate SEM. ${ }^{* *} p<0.01$ (one-way ANOVA with Tukey's multiple comparison test). SL (S63del-L), SH (S63del-H). B, CnA was visualized in teased fibers from sciatic nerve from P28 WT mice by immunostaining. Antibody anti-MBP (red) highlights myelin and Tuj-1 (cyan) the axon, while CnA (green) is localized in the perinuclear and nuclear (DAPI) regions. The staining was repeated twice with $n=3$ independent sets of WT nerves. Scale bar, $5 \mu \mathrm{m}$. Columns represent the percentage of (nA-positive cells in either Schwann cell cytoplasm (MBP) or axon (Tuj1). Error bars indicate SEM. ${ }^{* * *} p<0.001$ (Student's $t$ test). SC, Schwann cells. C, Immunofluorescence revealed CnA (magenta) in neuronal cell bodies (yellow arrowheads) and much less in axons (white arrows) stained with Tuj-1 (cyan) of adult DRGs from P28 mice. DAPI was used to highlight nuclei. The staining was performed on $n=3$ or 4 DRGs from 3 WT animals. Scale bar, $20 \mu \mathrm{m}$. Graph represents the mean of the percentage of (nA-positive neurons in either the cell body (yellow arrowheads) or axons (white arrows). Error bars indicate SEM. ${ }^{* * *} p<0.001$ (Student's $t$ test). $n=3$.

Schwann cells (D’Antonio et al., 2013; Das et al., 2015; Scapin et al., 2020). However, reduction of eIF2alpha phosphorylation by genetic ablation of PERK paradoxically improved myelination in S63del Schwann cells (Musner et al., 2016; Sidoli et al., 2016). To evaluate the effect of altered eIF2alpha phosphorylation on S63del myelin, we compared S63del/Perk ${ }^{S C K O}$ with a genetic model that specifically impairs eIF2alpha phosphorylation in Schwann cells (Scapin et al., 2020). We crossed P0Cre mice with the ubiquitous floxed WT eIF2alpha transgene $(f / \mathrm{Tg})$ in eIF2alpha ${ }^{\mathrm{A} / \mathrm{A}}$ background mice $(A / A ; f / T g)$ (Back et al., 2009), as previously reported (Scapin et al., 2020) (Fig. 1A). Briefly, in eIF2alpha ${ }^{\mathrm{A} / \mathrm{A}}$ mice, a nonphosphorylatable substitution of serine to alanine eIF2alpha ${ }^{\mathrm{A} / \mathrm{A}}$ causes a perinatal lethal effect that is rescued by the eIF2alpha ( $\mathrm{Tg}$ ) transgene expressed in all cells of the body, unless Cre recombines the floxed eIF2alpha transgene $(f)$. When crossed with P0Cre mice, the eIF2alpha $(\mathrm{Tg})$ transgene rescues the lethal effect of the nonphosphorylatable substitution of serine to alanine eIF2alpha ${ }^{\mathrm{A} / \mathrm{A}}$ in every cell except in Schwann cells where P0Cre drives recombination of eIF2alpha $(f / \mathrm{Tg})$ (Feltri et al., 1999). This strategy allowed us to specifically impair the phosphorylation of eIF2alpha in S63del Schwann cells without affecting other cell types (Fig. 1), and we refer to it as S63del/ $e I F 2 \alpha^{S C-A A}$ (Scapin et al., 2020). The comparison of S63del/ $e I F 2 \alpha^{S C-A A}$ and S63del/Perk ${ }^{\text {SCKO }}$ highlighted differences in myelin phenotypes despite eIF2alpha phosphorylation being significantly reduced in both genetic models (Fig. 1) (Sidoli, 2016; Scapin et al., 2020). Compared with S63del nerves, S63del/ $e I F 2 \alpha^{S C-A A}$ nerves are severely hypomyelinated (measured by the g-ratio; Fig. $1 B$ ) and small-caliber axons are amyelinated (Fig. $1 C$, red arrowheads), whereas $\mathrm{S} 63 \mathrm{del} / \operatorname{Perk}^{S C K O}$ nerves showed a moderate improvement compared with S63del nerves (Fig. $1 B, C$ ) (Sidoli, 2016; Scapin et al., 2020).

These results confirm that interfering directly with eIF2alpha phosphorylation worsens the S63del myelin phenotype (Scapin et al., 2020). Nonetheless, PERK ablation leads to the opposite effect, suggesting that PERK may modulate signals that are independent from eIF2alpha to improve S63del myelination.

\section{PERK binds calcineurin in S63del Schwann cells}

To understand why PERK ablation has a positive effect in S63del Schwann cells, we surveyed the major arms of the UPR pathway to find potential compensatory mechanisms but found no substantial change (Sidoli et al., 2016). Importantly, the amount of $\mathrm{P} 0$ retained in the ER of S63del/Perk ${ }^{\mathrm{SCKO}}$ was elevated, indicating an unresolved ER stress (Sidoli et al., 2016).

Here, we hypothesized that PERK may have an alternative role in the pathomechanism of S63del. PERK is a ubiquitous kinase with substrates other than eIF2alpha (Cullinan et al., 2003; Muñoz et al., 2013; van Vliet et al., 2017). Calcineurin phosphatase, for instance, binds PERK on ER stress in vitro and in vivo (Bollo et al., 2010; R. Wang et al., 2013; Liu et al., 2014; Chen et al., 2016), and its deletion in the neural crest lineage may impair myelination in P1 nerves (Kao et al., 2009). Given the developmental delay of S63del nerves (D’Antonio et al., 2013; Sidoli et al., 2016), we first hypothesized that PERK binds calcineurin on stress and blocks its activity causing delays in myelination. PERK indeed binds calcineurin in mature myelinating Schwann cells from P28 sciatic nerves through coimmunoprecipitation (Fig. $2 A$ ). In particular, CnA bound P-PERK (Thr-198) in S63delL (60\% mpz expression) and $\mathrm{S} 63 \mathrm{delH}(210 \% \mathrm{mpz}$ expression), but 
not in WT adult nerves (P28) (Fig. 2A). Notably, CnA protein was equal across all the genotypes, whereas P-PERK (Thr198) was visible mainly in $\mathrm{S} 63 \mathrm{delH}$ where the ER stress was most severe (Wrabetz et al., 2006; Musner et al., 2016) (Fig. 2A, input). Immunoblot analysis on sciatic nerves requires the lysis of the entire nerves, which consists mainly of Schwann cells but also axons, perineurial cells, and fibroblasts. By immunolabeling $\mathrm{CnA}$ in teased sciatic nerves from WT mice, we detected more CnA in Schwann cell cytoplasm than axons (Fig. 2B). Moreover, CnA localized mostly in neuronal cell bodies (Fig. 2C, yellow arrowheads) and rarely in the axons of adult DRG neurons (Fig. 2C, white arrows). Together, our data showed that calcineurin binds P-PERK in S63del adult nerves, where ER stress is persistently active, and that the binding most likely occurs in Schwann cells.

\section{Calcineurin signaling is high in S63del nerves}

Calcineurin is a heterodimer consisting of a catalytic subunit, $\mathrm{CnA}$, and a regulatory subunit, $\mathrm{CnB}$, that stabilizes $\mathrm{CnA}$ in absence of calcium (Klee et al., 1979; Aramburu et al., 2000; Rusnak and Mertz, 2000; Yang and Klee, 2000). Upon calcium elevation in the cytoplasm, CaM binds $\mathrm{CnB}$ to expose the active site of $\mathrm{CnA}$. $\mathrm{CnB}$ and $\mathrm{CaM}$ components of the calcineurin phosphatase complex are necessary to provide proper enzymatic function (Yang and Klee, 2000; Shen et al., 2008; H. Wang et al., 2008; RumiMasante et al., 2012; Mehta et al., 2014). We found minimal changes in CaM and $\mathrm{CnB}$ protein levels between $\mathrm{WT}$ and S63del (Fig. $3 A, B$ ). Since it was proposed that the phosphatase activity of calcineurin is required for myelin development (Kao et al., 2009), we asked whether such activity was reduced in S63del Schwann cells, thereby preventing proper myelination. On the contrary, calcineurin activity was significantly higher in nerve lysates from S63del mice and reduced only when lysates were incubated with EGTA before enzymatic assay (Fig. 3C) (Baykov et al., 1988; Geladopoulos et al., 1991).

To understand whether dysregulated calcium dynamics in S63del Schwann cells may contribute to increase calcineurin activity, we measured calcium flux using fura-2 ratio during time lapse imaging of embryonic DRGs (Fig. 3D-G). We induced myelination with ascorbic acid (AA) for $10 \mathrm{~d}$ in embryonic DRGs from WT and mutant mice, and then triggered calcium flux in myelinating (Fig. 3D-F) and nonmyelinating DRGs (Fig. $3 G$ ) by adding $100 \mathrm{~mm}$ ATP to the culture, in normal or
B
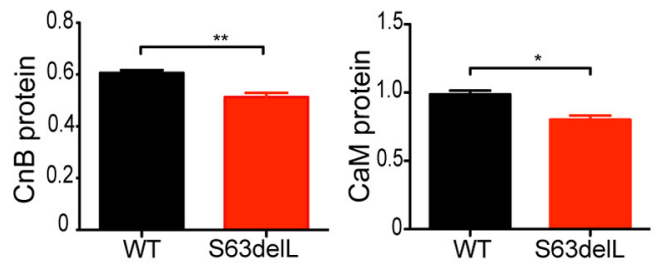

D
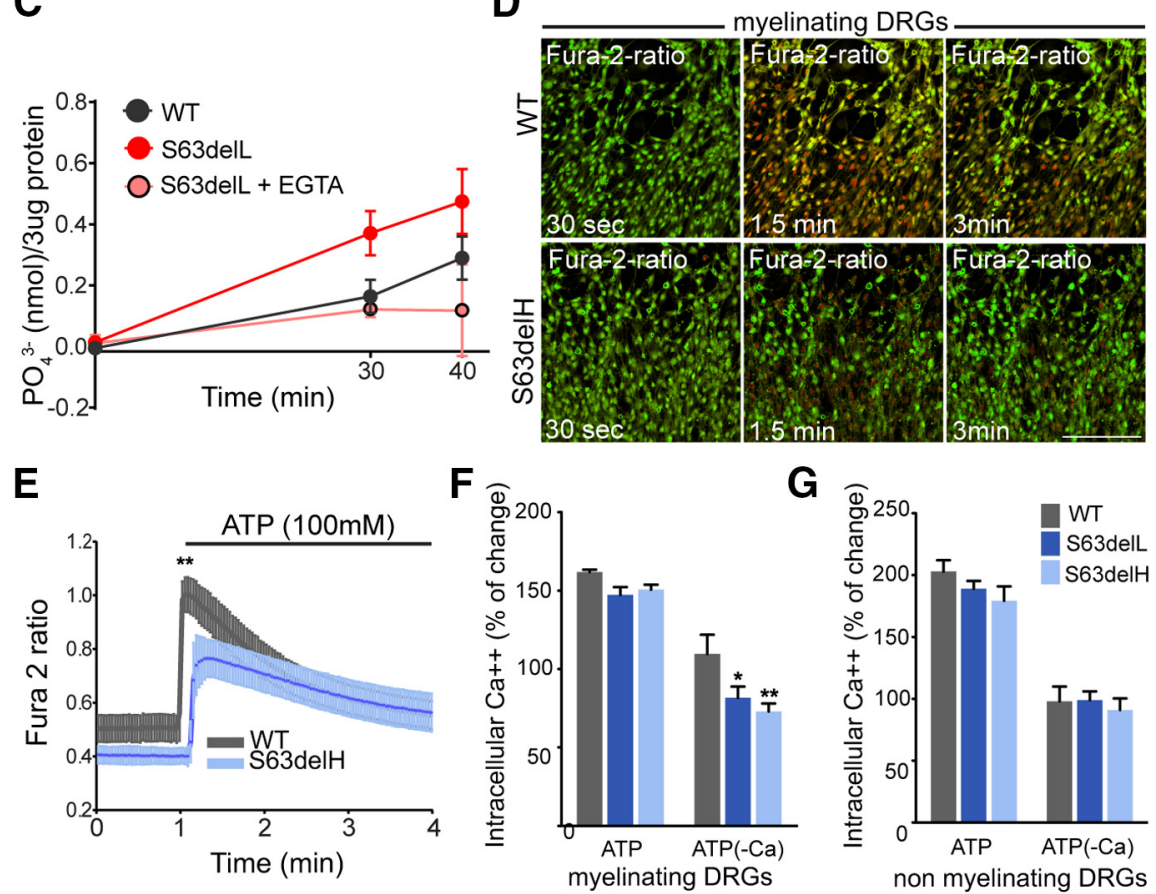

Figure 3. Calcineurin activity is increased in S63del nerves. $A, W B$ analysis revealed $\mathrm{CaM}$ and $\mathrm{CnB}$ in WT and S63del nerves from P28 mice. $\beta$-Tubulin (TUB) represents the loading control. $\boldsymbol{B}$, Graphs represent the quantification of the WB for $\mathrm{CnB}$ (left) and CaM (right). Error bars indicate SEM. ${ }^{*} p<0.05$; ${ }^{* *} p<0.01$; Student's $t$ test. $n=3$. C, Calcineurin activity was measured in WT and S63del nerves using a colorimetric assay with malachite green. Three nerves were pulled from each genotype to generate one sample lysate, and $3 \mu \mathrm{g}$ of lysate was used for the enzymatic assay (Enzo Life Sciences). As control S63del nerve, lysates were incubated with $20 \mathrm{~mm}$ EGTA to chelate calcium before enzymatic assay. The kinetic was measured at 30 and $40 \mathrm{~min}$. Graph represents 3 separate experiments. $n=3-6$ sample lysate per condition. $\boldsymbol{D}$-G, Myelinating (D-F) and nonmyelinating (G) DRG explants from WT, S63delL, and S63delH embryos (E13.5) were incubated with $4 \mu \mathrm{m}$ fura-2 AM and treated with ATP $(100 \mathrm{~mm})$ in media with or without calcium (-Ca). D, Frames from time lapse imaging of myelinating schwann cells from WT and S63delH mouse embryos cultured in calcium-free media to monitor changes of intracellular calcium concentration after $30 \mathrm{~s}, 1.5$ and $3 \mathrm{~min}$ of $100 \mathrm{~mm}$ ATP treatment, using fura-2 AM ratio. Red represents increased calcium concentration. Scale bar, $8 \mu \mathrm{m}$. $\boldsymbol{E}$, Calcium dynamics in myelinating WT and S63delH DRGs represented in $\boldsymbol{D}$ and resent the mean of percentage of calcium change from basal to ATP-induced levels, measured as change in fura- 2 ratio during time lapse imaging (D). Error bars indicate SEM. $n=3$. ${ }^{*} p<0.05 ;{ }^{* *} p<0.01$; Student's $t$ test.

calcium-depleted media (-Ca) (Fig. 3D-G). Schwann cells responds to axonal release of ATP through P2Y purinergic receptors, which elicit calcium flux from cellular storages, such as the ER (Ansselin et al., 1997; Green et al., 1997; Stevens and Fields, 2000). Only myelinating DRGs from S63del and S63delH (Fig. 3D-F), and not nonmyelinating DRGs (Fig. 3G), showed 20\%-30\% less calcium efflux compared with WT when stimulated with ATP in calcium-depleted media. This result indicates that chronic ER stress in S63del may elicit a significant dysregulation of calcium efflux from intracellular storages.

Downstream of calcium, calcineurin dephosphorylates NFAT transcription factors causing their nuclear translocation (Crabtree and Olson, 2002; Wu et al., 2007). Consistent 
A

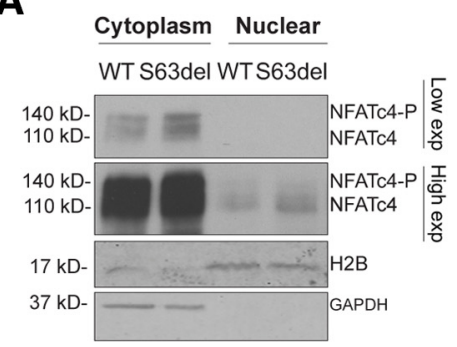

B

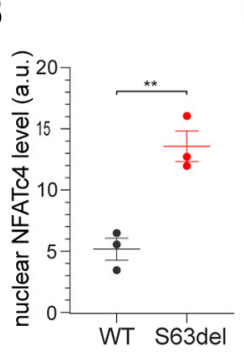

C

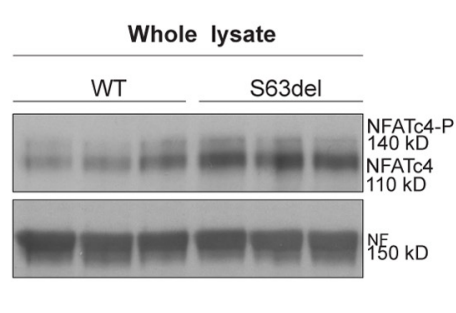

D

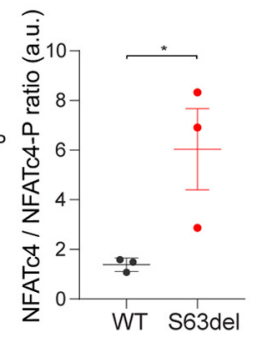

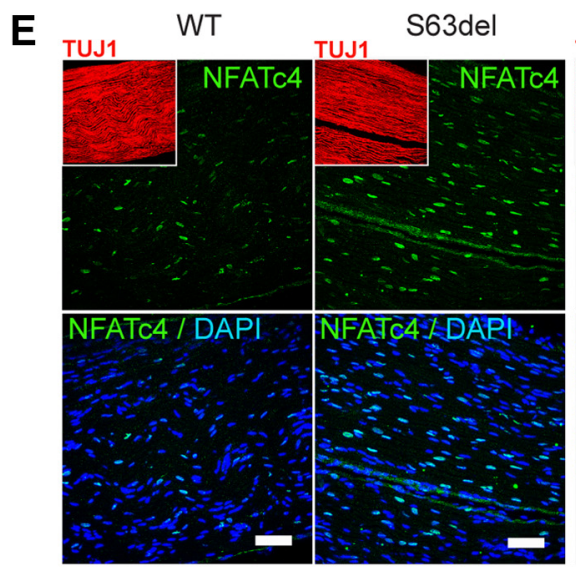
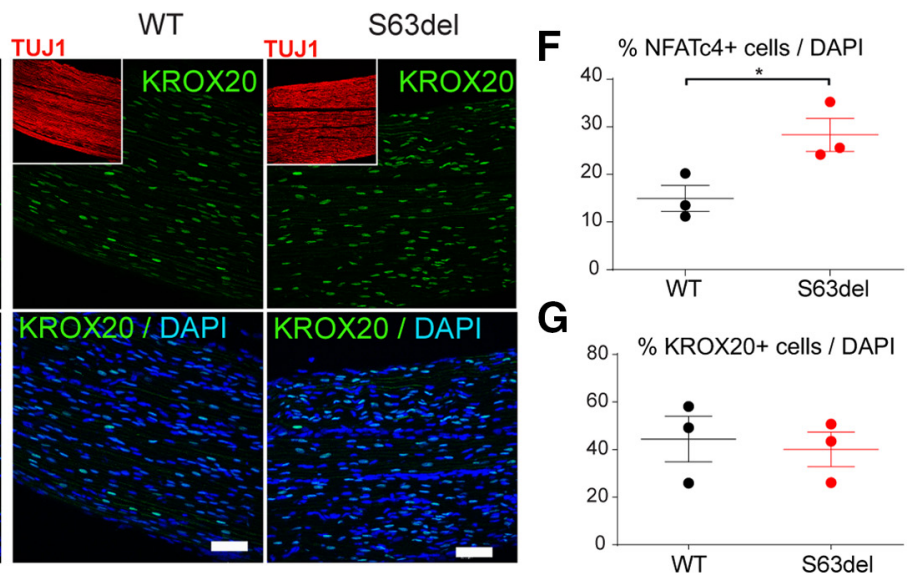

Figure 4. Nuclear NFATc4, but not Krox20, is increased in S63del nerves. $A$, Nuclear versus cytoplasmic enrichment of NFATc4 was obtained in WT and S63del sciatic nerves from P28 mice. Histone 2B (H2B) and GAPDH were used as marker of nuclear and cytoplasmic fraction, respectively. Nuclear NFATc4 appears with high exposure (High exp), whereas cytoplasmic NFATc4 is visible at lower exposure (Low exp). B, NFATc4 in the nuclear fraction was quantified in WT and S63del nerves, and H2B was used to normalize. Error bars indicate SEM. $n=3$. ${ }^{* *} p<0.01$ (Student's $t$ test). a.u., Arbitrary units. C, P28 sciatic nerves were homogenized from WT and S63del mice and incubated with NFATc4 antibody that recognizes phosphorylated (140 kDa) and nonphosphorylated NFATc4 (110 kDa). D, Quantified ratio of nonphosphorylated over phosphorylated NFATc4 protein level in C. Error bars indicate SEM. $n=3 .{ }^{*} p<0.5$ (Student's $t$ test). a.u., Arbitrary units. $\boldsymbol{E}$, longitudinal cryosections of WT and S63del sciatic nerves from P28 mice were incubated with antibody against NFATc4 and KR0X20 (green), Tuj1 for axons (red, insets), and DAPI for nuclei (blue). Scale bars, $50 \mu \mathrm{m} . \boldsymbol{F}, \mathbf{G}$, Graph represents the percentage (\%) of nuclei positive for NFATc4 and KROX20 (E) staining as function of total DAPI-stained cells. Error bars indicate SEM. ${ }^{*} p<0.05$ (Student's $t$ test). $n=3$.

with increased calcineurin activity, NFATc4 nuclear localization also increased in S63del Schwann cells from P28 nerves, as shown by nuclear/cytoplasmic fractionation (Fig. $4 A, B$ ), WB of whole nerve lysate (Fig. 4C,D), and immunofluorescence (Fig. 4E,F). Interestingly, the nuclear expression of the transcription factor KROX20 did not increase in S63del (Fig. 4E,G). This is consistent with recent observations from our laboratory showing that KROX20 expression is independent of calcineurin activity in mature myelinating Schwann cells (Reed et al., 2020).

\section{PERK ablation modulates calcineurin activity in S63del nerves}

Our data so far do not support the hypothesis that PERK activation reduces calcineurin activity in S63del nerves, preventing proper myelination. We found instead a remarkable induction of calcineurin-NFATc4 signal in S63del nerves. Given that S63del nerves in C57/BL6 mice present a developmental delay (D’Antonio et al., 2013; Sidoli et al., 2016), we asked whether and to which extent PERK regulates the expression of Schwann cell regulatory genes and the activity of calcineurin. Markers for immature Schwann cells, such as Oct6, Sox2, and c-Jun, were highly expressed in P28 S63del nerves compared with WT (Fig. $5 A$ ), as previously reported (D'Antonio et al., 2013; Florio et al., 2018) and remained equally elevated in S63del/Perk ${ }^{\mathrm{SCKO}}$ (Fig. 5A). Differently, Sox10, Nfatc4, and Yy1 mRNA levels were similar in WT, S63del, and S63del/Perk ${ }^{\mathrm{SCKO}}$ nerves (Fig. $5 A$ ). In addition, PERK loss of function moderately, but not significantly, increased Krox20 mRNA (Fig. 5B) and protein levels (not shown) and enhanced calcineurin activity in S63del nerves (Fig. $5 E$ ). This result is not likely because of altered protein levels of $\mathrm{CnB}$ and $\mathrm{CaM}$, which were similar between the genotypes (Fig. $5 C, D)$. In conclusion, PERK loss of function induces calcineurin activity without altering myelin gene expression in S63del nerves.

\section{Removing CnA in neuropathic DRG rescues in vitro myelination}

The upregulation of calcineurin signal in pathologic Schwann cells has never been shown before and prompted us to investigate the role of calcineurin in the context of the S63del mutation using genetic approaches in vitro and in vivo. P-PERK binds the catalytic subunit of calcineurin $\mathrm{CnA}$, which exists in two isoforms (CnAalpha and CnAbeta). CnAalpha is the most abundant isoform in the nervous system (Rusnak and Mertz, 2000; Bollo et al., 2010). Global CnAalpha-deficient mice were particularly difficult to obtain because of early postnatal lethality for digestive failure, despite the repeated attempts to rescue pups with food supplements (Reddy et al., 2011; Madsen et al., 2013). Since CnAalpha-deficient E13.5 embryos were viable, we first turned to the DRG system and induced myelination in vitro using AA (Fig. 6). After 5 and $12 \mathrm{~d}$ of AA treatment, we quantified the number of myelin internode stained with $\mathrm{MBP}$ while axons were highlighted with Tuj1 (Fig. 6A,B). Notably, while CnA protein is nearly absent in CnAalpha ${ }^{-1-}$ DRGs, CnB subunit is also remarkably reduced (Fig. 6D). In WT DRGs, the number of myelin internodes increased from an average of 180 internodes after $5 \mathrm{~d}$ of AA to an average of 270 internodes after $12 \mathrm{~d}$, while 
in S63del DRG myelination was already reduced at day 5 and it remained low at day 12 (Fig. 6C). The absence of CnAalpha by itself did not alter the number of myelin internodes in a normal background compared with WT DRGs (Fig. 6A-C) consistent with recent work from our laboratory (Reed et al., 2020). However, CnAalpha removal in the S63del background increased DRG myelination (Fig. 6A-C). In addition, the quantification indicated that CnAalpha ablation rescued S63del myelination already after $5 \mathrm{~d}$ of $\mathrm{AA}$ but did not further improve it at $12 \mathrm{~d}$ of AA (Fig. $6 \mathrm{C}$ ). The restoration of S63del hypomyelination in DRGs with the reduction in CnAalpha suggests a gain of function of the phosphatase activity in diseased DRGs.

\section{Calcineurin activity has to be tightly regulated in S63del nerves}

Abnormal activation of calcineurin in S63del Schwann cells may represent a pathologic toxic gain of function. Indeed, Schwann cells from S63del DRGs benefit from global CnAalpha deletion (Fig. 6). However, the presence of DRG neurons in our experiments hinders any cell autonomous information. Therefore, we crossed $\mathrm{CnB}$ fl/fl (Neilson et al., 2004) with P0Cre mice (Feltri et al., 1999) to specifically eliminate $C n B$ in myelinating Schwann cells, hereafter referred to as $\mathrm{CnB}^{\mathrm{SCKO}}$. We assessed the efficiency of Cre/lox recombination by $\mathrm{WB}$ and confirmed that the protein levels of the regulatory subunit $\mathrm{CnB}$ and of the catalytic subunit CnA were both reduced (Fig. 7A,B) (Reed et al., 2020). The WB of $C n B^{\mathrm{SCKO}}$ sciatic nerves shows a residual protein level of $\mathrm{CnA}$ and $\mathrm{CnB}$ compared with WT (Fig. 7A,B), which may derive from other cell types, such as blood cells or epineurium. Indeed, Schwann cells isolated from $C n B^{\text {scko }}$ sciatic nerves showed almost complete reduction in both $\mathrm{CnB}$ and $\mathrm{CnA}$ proteins, confirming the specificity of this model (Reed et al., 2020). EM of P28 nerves confirmed the presence of thin myelin (Fig. $7 C$ ) and many amyelinated axons in S63del nerves (Fig. 7C, red arrowhead) (D'Antonio et al., 2013; Musner et al., 2016; Sidoli et al., 2016). The loss of $C n B$ alone did not affect myelin thickness or the percentage of amyelinated axons (Fig. 7D,E) (Reed et al., 2020). Similarly, the loss of one or both $C n B$ alleles in S63del had no effect on the myelin thickness compared with S63del (Fig. $7 E$ ). Instead, the complete loss of $C n B$ in S63del slightly increased the percentage of amyelinated fibers compared with S63del nerves (Fig. 7C,D, red arrowheads). These data indicate that in vivo calcineurin may instead have a protective role in S63del sciatic nerves at P28, during the peak of myelination and ER stress (Pennuto et al., 2008; D’Antonio et al., 2013). Importantly, Perk loss of function reduces the percentage of amyelinated axons in $\mathrm{S} 63 \mathrm{del} / \mathrm{CnB} B^{\mathrm{SCKO}}$ (Fig. $7 C, D$ ), suggesting that Perk may genetically interact with calcineurin as a downstream effector for S63del myelin defects.
Similarly, to the P28 analyses, the loss of $C n B$ in S63del had no effect on myelin thickness at P10 (Fig. 8A,B). However, P10 $\mathrm{S} 63 \mathrm{del} / \mathrm{Cn} B^{\mathrm{SCKO}}$ nerves had a small, but significant, reduction in the percentage of amyelinated fibers compared with S63del (Fig. $8 A$, white asterisks, $C$ ). This result suggests that $C n B$ deletion causes a small rescue during early myelination and beginning of ER stress (Pennuto et al., 2008). However, electron micrographs revealed more degenerating axons (Fig. $8 A$, red arrowhead, $D$ ) and multiple abnormal myelin structures (Fig. $8 A$, white arrow, $E)$, when calcineurin was completely removed in S63del Schwann cells (Fig. 8D,E), suggesting again a protective role for calcineurin in pathology. Overall, our in vivo data only partially support the hypothesis that increased calcineurin activity is deleterious, but also point out that complete loss of calcineurin aggravates aspects of the phenotype in the context of ER stress.

Thus, we provide evidence that calcineurin signal is upregulated in CMT1B neuropathy and that both too much or too little calcineurin activity aggravates the phenotype. This suggests that the ER stress environment renders Schwann cells extremely sensitive to any changes in calcineurin dosage or temporal regulation.

\section{Discussion}

The phosphorylation of eIF2alpha reduces the synthesis of misfolded proteins, which is crucial to maintain Schwann cell health and function in P0S63del/CMT1B neuropathy (D'Antonio et al., 
A
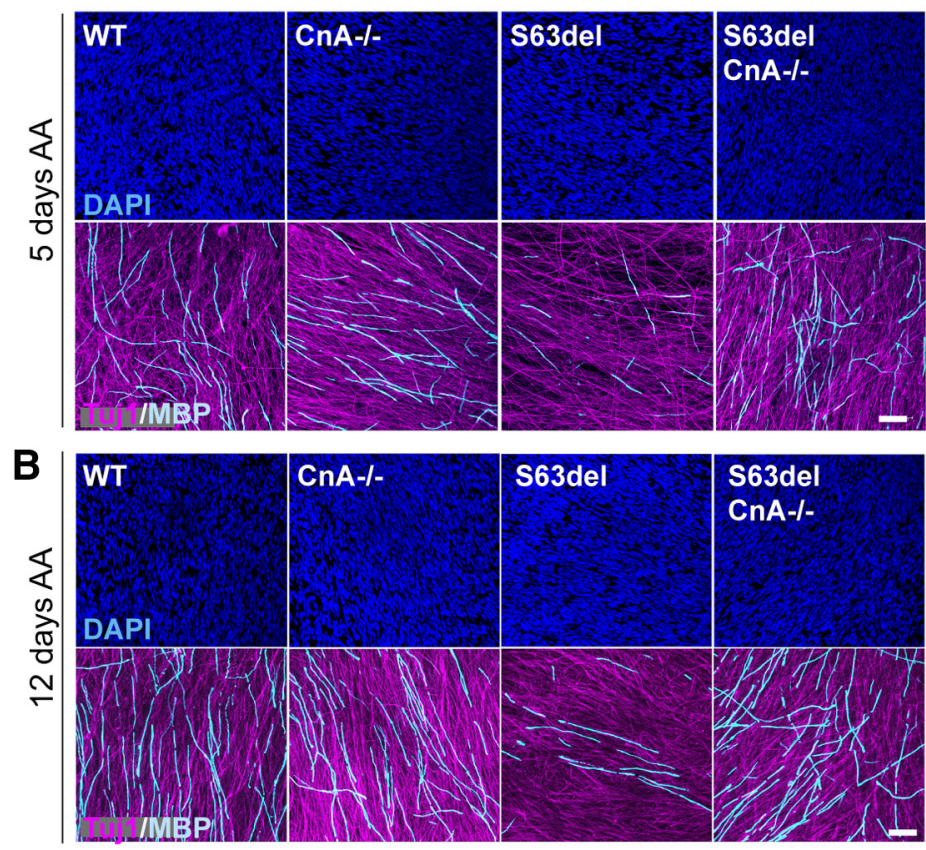

C
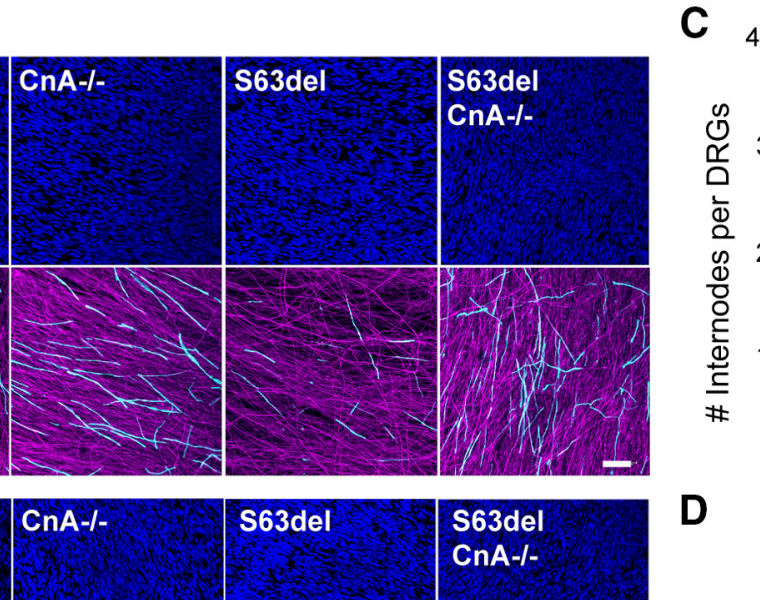

12 days $A A$

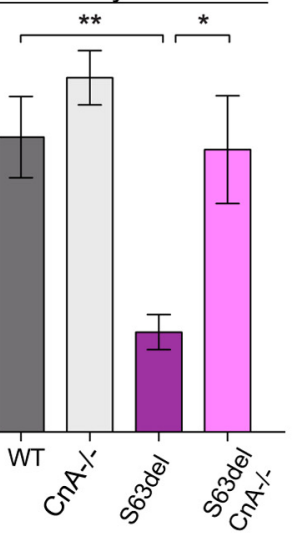

10 days $A A$
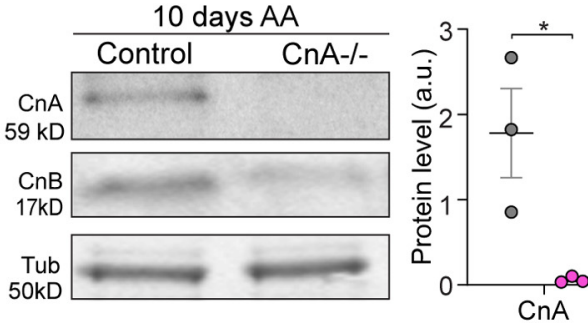

OControl O CnA-/-
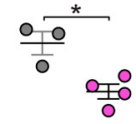

$\mathrm{CnA}$

$\mathrm{CnB}$

Figure 6. Ablation of $\mathrm{CnA}$ in DRG explants improves S63del hypomyelination in vitro. DRGs were dissected from E13.5 embryos, and myelination was induced with $50 \mu \mathrm{g} / \mathrm{ml}$ of $\mathrm{AA}$ after $5 \mathrm{~d}$ in culture. $\boldsymbol{A}, \boldsymbol{B}$, In vitro myelination was assessed in WT, $C n A^{-1-}$, S63del, and S63del/ $C n A^{-1-}$ DRGs. Myelin was visualized by MBP staining (cyan) on DRGs after 5 ( $\left.\boldsymbol{A}\right)$ and $12 \mathrm{~d}(\boldsymbol{B})$ of AA treatment. Axon and nuclei were also revealed with Tuj-1 (magenta) and Dapi (blue), respectively. Scale bar, $50 \mu \mathrm{m}$. $\boldsymbol{C}$, Graphs represent MBP quantification $(\boldsymbol{A}, \boldsymbol{B})$. $n=30-108$ acquisitions from 5-18 DRGs per genotype. DRGs were isolated from E13.5 embryos from 3 different female mice, in two separate dissections. Error bars indicate SEM. ${ }^{*} p<0.05$; ${ }^{* *} p<0.01 ;$ one-way ANOVA with Bonferroni's multiple comparison. D, Left, WB for $\mathrm{CnA}$ and $\mathrm{CnB}$ was performed on WT and $\mathrm{CnA}^{+/-}$(Control) and $\mathrm{CnA}^{-1-}$ DRGs after $10 \mathrm{~d}$ of myelination. $\beta$-Tubulin (Tub) was used as loading control. Right, Graph represents the mean of CnA and CnB WB in controls and $C n A^{-1-}$ DRGs. Error bars indicate SEM. * $p=0.01$ (Student's $t$ test).

2013; Das et al., 2015). Indeed, preventing directly eIF2alpha phosphorylation in S63del Schwann cells dramatically exacerbates myelin morphology (Fig. 1) (Scapin et al., 2020). Among eIF2alpha kinases (PKR, HRI, GCN2, and PERK), PERK is the most active in S63del nerves and its deletion paradoxically improves myelin morphology despite reduction of eIF2alpha phosphorylation (Musner et al., 2016; Sidoli et al., 2016) (Fig. 1). We therefore reasoned that PERK may interfere with Schwann cell development via alternative pathways other than the UPR. Indeed, we showed that PERK and calcineurin interact in CMT1B Schwann cells, that calcineurin is more active in S63del than WT Schwann cells, and that PERK ablation slightly increases this activity further. To our knowledge, this is the first report that calcineurin signal is upregulated in Schwann cells on ER stress (Fig. 9B). We asked whether the nature of this activity was toxic or adaptive and found that removing $C n A$ improves myelination in S63del DRG explants, whereas targeted deletion of $\mathrm{CnB}$ in Schwann cells slightly worsens myelin and axon morphology of S63del nerves (Fig. 9C). Our in vivo results indicate that calcineurin levels must be tightly regulated in stressed S63del Schwann cells and the discrepancies between DRG and mouse data are indications that Schwann cells may be very sensitive to calcineurin manipulation in a context-dependent manner (Fig. 9). Small changes in the dosage, alterations of the subunits, and the timing of calcineurin activity may affect Schwann cell behavior in S63del myelination.

PERK interaction with calcineurin in S63del Schwann cells PERK is the UPR transducer responsible for reducing the translation of misfolded proteins in the ER (Scheuner et al., 2001; Wek and Cavener, 2007; Hollien, 2013; Liu et al., 2015). Despite
PERK signaling being commonly considered beneficial to cope with ER stress, there is growing evidence also showing the opposite. Indeed, while PERK is essential in cell types with intensive protein synthesis and secretion, such as pancreatic cells, hepatocytes, and osteoblasts (Harding et al., 2000a,b, 2001; Scheuner et al., 2001; P. Zhang et al., 2002; Wei et al., 2008; Saito et al., 2011), PERK signaling is detrimental in many neurodegenerative diseases and psychiatric disorders, including amyotrophic lateal sclerosis, prion disease, and dementia (Moreno et al., 2013; Kim et al., 2014; Radford et al., 2015; Smith et al., 2020). In oligodendrocytes, the myelinating glia of the CNS, dysregulation of PERK-eIF2alpha phosphorylation causes vanishing white matter disease and worsens the clinical outcome of the EAE model of multiple sclerosis (Proud, 2001; Lin et al., 2007). In S63del Schwann cells, PERK seems to have acquired divergent and context-dependent functions. Direct impairment of eIF2alpha phosphorylation severely aggravates myelin morphology of S63del nerves (Scapin et al., 2020), whereas increasing eIF2alpha phosphorylation rescues morphologic and functional deficits of S63del nerves (D'Antonio et al., 2013; Das et al., 2015). Perk deletion reduces eIF2alpha phosphorylation and yet improves myelin morphology of S63del nerves (Sidoli et al., 2016), indicating that PERK may control different pathways in Schwann cells in addition to translation and possibly via alternative substrates. Studies reported that PERK phosphorylates nuclear factor erythroid 2related factor 2 transcription factor and interacts with Mitofusin 2 mitochondrial protein and the actin binding protein Filamin A (Cullinan et al., 2003; Muñoz et al., 2013; van Vliet et al., 2017). Other studies show that PERK interacts physically and functionally with calcineurin phosphatase (Bollo et al., 2010; Liu et al., 2014; Chen et al., 2016). Once activated, P-PERK binds and 
phosphorylates the catalytic subunit CnA limiting its activity on ER stress (Bollo et al., 2010). In agreement, we show that calcineurin interacts with P-PERK mostly in S63del Schwann cells (Fig. 2). The role of calcineurin in Schwann cells is still being understood. Deletion of calcineurin in neural crest cells blocks Schwann cell differentiation up to postnatal day 1 (Kao et al., 2009), while recent work has demonstrated that the deletion in committed myelinating Schwann cells slightly delays Schwann cell development but does not alter myelin formation up to 6 months of age (Reed et al., 2020). On the other hand, the loss of calcineurin in adult Schwann cells limits autophagy and myelin clearance on injury (Reed et al., 2020), revealing a more important role of calcineurin in Schwann pathology than normal physiology.

\section{Calcineurin activity is upregulated in S63del nerves}

KROX20 regulates the expression of myelin proteins and is necessary for Schwann cell maturation (Topilko et al., 1994; Blanchard et al., 1996; Ghislain and Charnay, 2006). Whether KROX20 is directly downstream of calcineurin-NFATc4 remains controversial. Loss of calcineurin in immature Schwann cells reduces KROX20 expression and arrests Schwann cells development, whereas loss of calcineurin in mature Schwann cells does not (Kao et al., 2009; Reed et al., 2020). In S63del nerves, even abnormal calcineurin activity and increased nuclear localization of NFATc4 do not alter KROX20 expression consistent with previous work showing that modulation of NFATc4 alone is insufficient to modulate KROX20 expression (Kipanyula et al., 2013). As shown in previous studies, the data presented here indicate that S63del delays Schwann cell development (D'Antonio et al., 2013; Florio et al., 2018).

What triggers calcineurin-NFATc4 upregulation in S63del Schwann cells is not known, although calcium is the likely candidate (Klee et al., 1979; Yang and Klee, 2000). Calcium is abundantly stored in the ER to support protein-folding by chaperones (Kuznetsov et al., 1992; Vervliet et al., 2012), and it leaks out of the ER on UPR activation (Bonilla et al., 2002; Huang et al., 2006; Mekahli et al., 2011; Shinde et al., 2016). Calcium-dependent activity of calcineurin is at the basis of many diseases, including amyotrophic lateral sclerosis, retinal degeneration, neuropathic pain, and diabetic polyneuropathy (Fernyhough and Calcutt, 2010; Prell et al., 2013; Sharma et al., 2013; Shinde et al., 2016). Functional interaction of calcium-calcineurin and PERK has also been shown to be protective in the context of ER stress to promote cell survival (Bonilla et al., 2002; Bollo et al., 2010; Chen et al., 2016). Normally, axonal ATP increases intracellular calcium in Schwann cells (Stevens and Fields, 2000; Stevens et al., 2004); but when S63del DRG explants are treated with ATP in calcium-free media, Schwann cells release significantly less calcium compared with WT DRGs. Calcium-free media
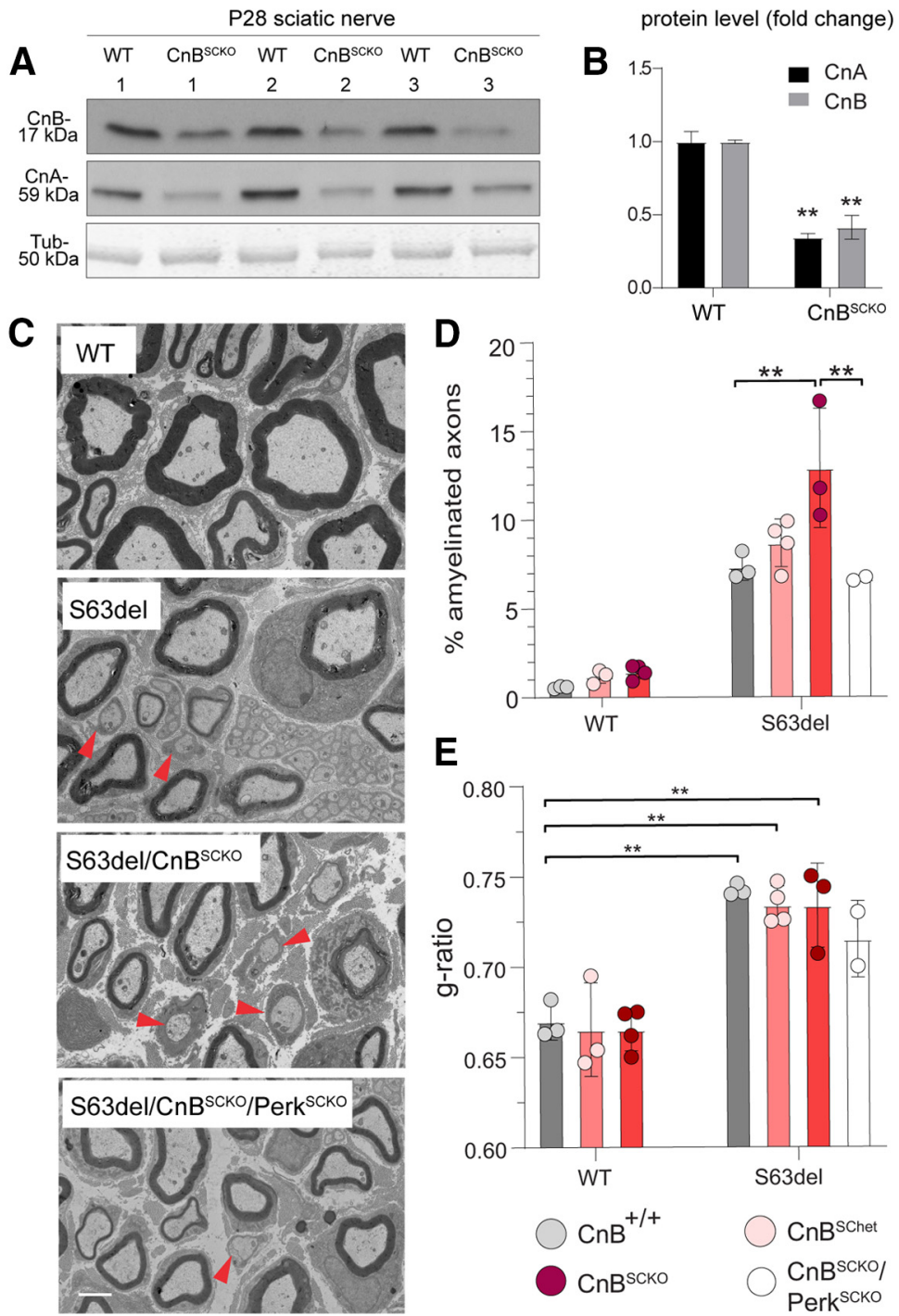

Figure 7. Ablation of $\mathrm{CnB}$ in S63del Schwann cells in P28 sciatic nerves. $A$, WB for $\mathrm{CnA}$ and $\mathrm{CnB}$ was performed in P28 sciatic nerves from WT and $C n B^{S C K 0}$ mice. $\beta$-Tubulin (Tub) represents the control for loading. $\boldsymbol{B}$, Quantification of $\%$ of amyelinated axons (red arrowheads) $(\boldsymbol{D})$ and g-ratio $(\boldsymbol{E})$ was performed over a total number test. Although it is not shown, all the WT genotypes were statistically significant against the S63del genotypes in the quantifications of \% of amyelinated axons, as previously reported (Sidoli et al., 2016).

allows the measurement of intracellular calcium dynamics; thus, our data suggest that intracellular storages, such as the ER, are defective in S63del Schwann cells perhaps because of UPR-dependent calcium leakage (Mekahli et al., 2011). Although more experiments are required to confirm, for instance, the resting calcium concentration in the cytoplasm versus the ER, these observations indicate that calcium dysregulation may be involved in calcineurin upregulation in S63del Schwann cells (Fig. 9B).

\section{The role of calcineurin in S63del Schwann cells}

Calcineurin activity has been shown to be both toxic and beneficial in several ER stress-related diseases (Mukherjee and Soto, 2011). For instance, calcineurin-NFAT activation mediates neuronal damage in models of Alzheimer's disease and Parkinson's disease (Wu et al., 2010; Luo et al., 2014), and blocking 
A
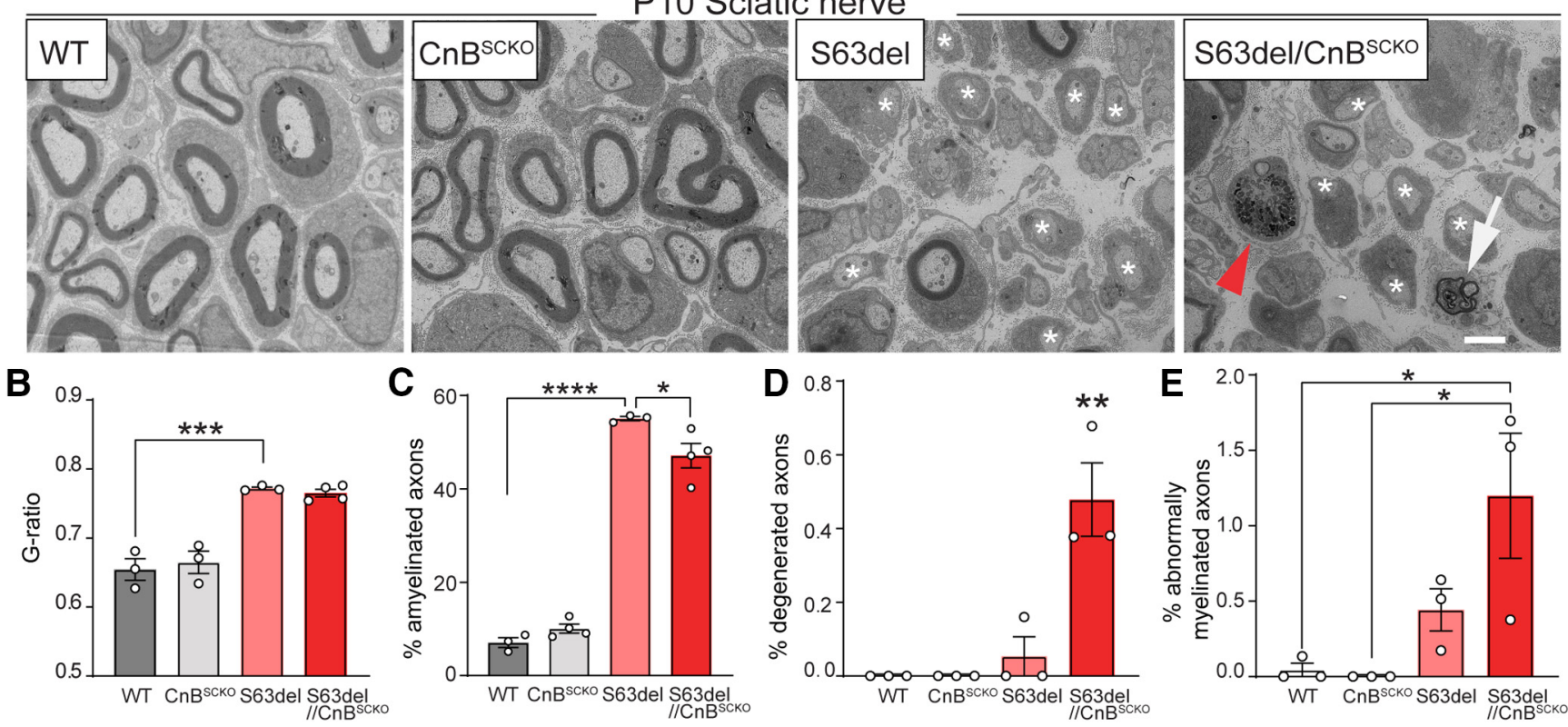

Figure 8. Ablation of $\mathrm{CnB}$ in S63del Schwann cells in P10 sciatic nerves. $A$, EM of P10 sciatic nerves of WT, $C n B^{S C K 0}, S 63$ del, and S63del $/\left(n B^{S C K 0}\right.$ mice. Scale bar, $2 \mu \mathrm{m}$. From the EM acquisitions, we quantified g-ratio (B), \% of amyelinated axons (white asterisks) ( $(\boldsymbol{C}, \%$ of degenerated axons (red arrowhead) (D), and \% abnormally myelinated axons (white arrow) (E) using 400500 axon from 3 or 4 animals. Error bars indicate SEM. ${ }^{*} p<0.05 ;{ }^{* *} p<0.01 ;{ }^{* * *} p<0.001$; ${ }^{* * *} p<0.0001$; one-way ANOVA with Tukey's multiple comparison test.

\section{A}
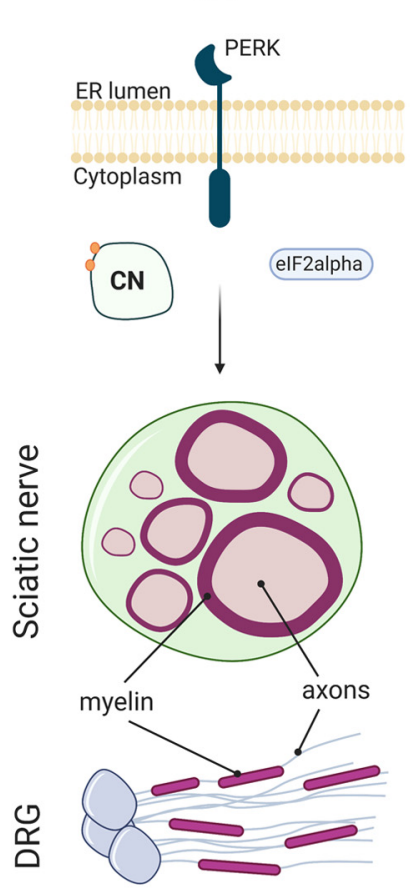

normal myelination
B
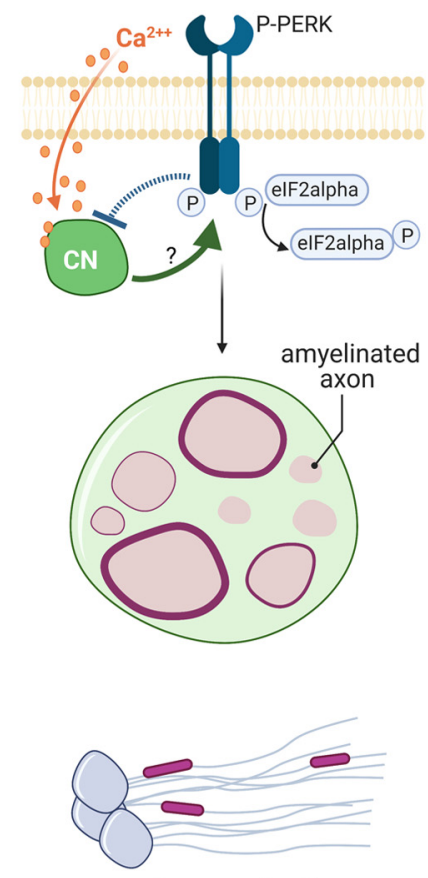

hypomyelination

\section{C $_{\text {S63del/Calcineurin KO }}$}
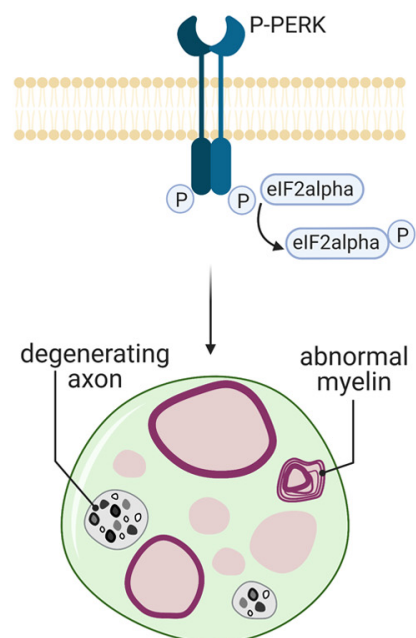

worse hypomyelination axonal degeneration

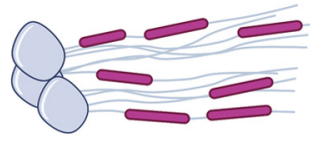

rescued myelination

\section{Created with BioRender.com}

Figure 9. Summary diagram. POS63del causes myelin defects in vivo (sciatic nerves) and in vitro (DRGs) (A). In S63del Schwann cells, PERK dimerize and autophosphorylate causing elF2alpha phosphorylation while calcineurin (CN) activity increases $(\boldsymbol{B})$. CN activation is likely triggered by the increased calcium flux out of the cell storages, such as the ER, and may be modulated by P-PERK (B). Vice versa, calcineurin may act on PERK function with a feedback loop. Here we show that calcineurin may be protective in S63del; indeed, calcineurin loss of function worsens myelination and causes axonal degeneration in vivo (C). However, loss of calcineurin improves myelination in S63del DRGs, suggesting that S63del Schwann cells are sensitive to calcineurin activity, which can be protective or toxic depending on the context. 
calcineurin activity reduced brain degeneration, improved motor performance, and promoted survival in prion-infected mice (Mukherjee et al., 2010). In contrast, inhibition of calcineurin impairs insulin secretion from $\beta$ cells with implications in diabetes and increases cerebral damage in mouse model of brain injury (R. Wang et al., 2013; Chen et al., 2016). Interestingly, the works cited above show that calcineurin's protective function was in concert with PERK activity. Our work reveals a complex, yet crucial, function for calcineurin in the context of pathologic S63del myelination. The complete deletion of the catalytic subunit CnAalpha improves in vitro myelination of S63del DRG explants, whereas the selected deletion of the regulatory subunit $\mathrm{CnB}$ in Schwann cells in vivo worsens myelin morphology and leads to an increase in the degeneration of axons. The different calcineurin subunit and the lack of cell autonomy in the DRG setting may account for the in vitro versus in vivo discrepancy. Indeed, most tissues express two catalytic isoforms of $\operatorname{CnA}$ ( $\alpha$ and $\beta$ ), which may have different functions (Aitken et al., 1984; Hubbard and Klee, 1989; Rusnak and Mertz, 2000; Gooch et al., 2004; Chen et al., 2016). DRGs were deficient of $\operatorname{CnA} \alpha$ but not $\operatorname{CnA} \beta$, which could potentially bind the residual amount of $\mathrm{CnB}$ to compensate. This scenario would identify $\operatorname{CnA} \beta$ as positive myelin regulator in stress condition as already shown in brain injury models (Chen et al., 2016). Second, the loss of $\mathrm{CnA} \alpha$ in DRG neurons may contribute to ameliorate myelination in vitro in a non-cell-autonomous way. Using the conditional floxed allele for $C n B$ and P0Cre allowed us to specifically remove calcineurin in Schwann cells. The complete abrogation of calcineurin in vivo worsens myelin morphology of S63del nerves of P10 and P28 mice. The only exceptions are P10 S63del nerves in which lack of $\mathrm{CnB}$ decreases the percentage of amyelinated axons resembling the DRG results. These apparently contradictory data suggest that stressed Schwann cells are very sensitive to the amount of calcineurin activity, which must be tightly regulated in CMT1B neuropathy. Notably, Perk deletion increments calcineurin activity and slightly upregulates Krox20 mRNA in S63de, suggesting that PERK interaction with calcineurin may limit its activity during ER stress. However, this calcineurin enhanced activity is not likely responsible for the beneficial effect of PERK loss of function in S63del neuropathy (Musner et al., 2016; Sidoli et al., 2016). Indeed, simultaneous deletion of $\mathrm{CnB}$ and Perk improves myelin formation in S63del compared with the deletion of $C n B$ alone. This genetic interaction is also suggesting that Perk may be downstream of calcineurin activity, and further work is necessary to establish how calcineurin and Perk interact to modulate S63del and other diseases of myelin where ER stress and calcium-calcineurin signaling cross paths. Calcineurin can still be a substrate of PERK kinase, and perhaps calcineurin has a relevant feedback effect on PERK activity crucial for myelin regulation during ER stress (Fig. 9B).

In conclusion, together with the recent work from our laboratory (Reed et al., 2020), the present results suggest that calcineurin function in Schwann cells is more important in a pathologic setting rather than in a developmental setting, and far more complex than what was previously reported. In particular, the regulation of calcium dynamics and downstream signaling of calcineurin in CMT1B neuropathy remain puzzling. Although calcineurin is known to promote the activation of NFAT transcription factors in PNS and CNS (Kao et al., 2009; Weider et al., 2018), it can dephosphorylate many other substrates, including NMDARs and TFEB (Lieberman and Mody, 1994; Tong et al.,
1995; Medina et al., 2015; Martina and Puertollano, 2018). Indeed, we recently demonstrated that calcineurin is required in Schwann cells to fully activate TFEB after injury (Reed et al., 2020). Future experiments are required to clarify the role of calcineurin and its potential substrates in S63del and in other pathologic settings to better our understanding of calcineurin in myelinating glial cells.

\section{References}

Aitken A, Klee CB, Cohen P (1984) The structure of the B subunit of calcineurin. Eur J Biochem 139:663-671.

Ansselin AD, Davey DF, Allen DG (1997) Extracellular ATP increases intracellular calcium in cultured adult Schwann cells. Neuroscience 76:947955.

Aramburu J, Rao A, Klee CB (2000) Calcineurin: from structure to function. Curr Top Cell Regul 36:237-295.

Back SH, Scheuner D, Han J, Song B, Ribick M, Wang J, Gildersleeve RD, Pennathur S, Kaufman RJ (2009) Translation attenuation through eIF2alpha phosphorylation prevents oxidative stress and maintains the differentiated state in beta cells. Cell Metab 10:13-26.

Baykov AA, Evtushenko OA, Avaeva SM (1988) A malachite green procedure for orthophosphate determination and its use in alkaline phosphatase-based enzyme immunoassay. Anal Biochem 171:266-270.

Blanchard AD, Sinanan A, Parmantier E, Zwart R, Broos L, Meijer D, Meier C, Jessen KR, Mirsky R (1996) Oct-6 (SCIP/Tst-1) is expressed in Schwann cell precursors, embryonic Schwann cells, and postnatal myelinating Schwann cells: comparison with Oct-1, Krox-20, and Pax-3. J Neurosci Res 46:630-640.

Bollo M, Paredes RM, Holstein D, Zheleznova N, Camacho P, Lechleiter JD (2010) Calcineurin interacts with PERK and dephosphorylates calnexin to relieve ER stress in mammals and frogs. PLoS One 5:e11925.

Bonilla M, Nastase KK, Cunningham KW (2002) Essential role of calcineurin in response to endoplasmic reticulum stress. EMBO J 21:2343-2353.

Chen Y, Holstein DM, Aime S, Bollo M, Lechleiter JD (2016) Calcineurin $\beta$ protects brain after injury by activating the unfolded protein response. Neurobiol Dis 94:139-156.

Crabtree GR, Olson EN (2002) NFAT signaling: choreographing the social lives of cells. Cell 109:S67-S79.

Cullinan SB, Zhang D, Hannink M, Arvisais E, Kaufman RJ, Diehl JA (2003) Nrf2 is a direct PERK substrate and effector of PERK-dependent cell survival. Mol Cell Biol 23:7198-7209.

D’Antonio M, Feltri ML, Wrabetz L (2009) Myelin under stress. J Neurosci Res 87:3241-3249.

D'Antonio M, Musner N, Scapin C, Ungaro D, Del Carro U, Ron D, Feltri ML, Wrabetz L (2013) Resetting translational homeostasis restores myelination in Charcot-Marie-Tooth disease type 1B mice. J Exp Med 210:821-838.

Das I, Krzyzosiak A, Schneider K, Wrabetz L, D’Antonio M, Barry N, Sigurdardottir A, Bertolotti A (2015) Preventing proteostasis diseases by selective inhibition of a phosphatase regulatory subunit. Science 348:239242.

Feltri ML, D’Antonio M, Previtali S, Fasolini M, Messing A, Wrabetz L (1999) P0-Cre transgenic mice for inactivation of adhesion molecules in Schwann cells. Ann NY Acad Sci 883:116-123.

Fernyhough P, Calcutt NA (2010) Abnormal calcium homeostasis in peripheral neuropathies. Cell Calcium 47:130-139.

Florio F, Ferri C, Scapin C, Feltri ML, Wrabetz L, D’Antonio M (2018) Sustained expression of negative regulators of myelination protects Schwann cells from dysmyelination in a Charcot-Marie-Tooth 1B mouse model. J Neurosci 38:4275-4287.

Geladopoulos TP, Sotiroudis TG, Evangelopoulos AE (1991) A malachite green colorimetric assay for protein phosphatase activity. Anal Biochem 192:112-116.

Ghislain J, Charnay P (2006) Control of myelination in Schwann cells: a Krox20 cis-regulatory element integrates Oct6, Brn2 and Sox10 activities. EMBO Rep 7:52-58.

Gooch JL, Toro JJ, Guler RL, Barnes JL (2004) Calcineurin A-alpha but not A-beta is required for normal kidney development and function. Am J Pathol 165:1755-1765. 
Green AC, Dowdall MJ, Richardson CM (1997) ATP acting on P2Y receptors triggers calcium mobilization in Schwann cells at the neuroelectrocyte junction in skate. Neuroscience 80:635-651.

Harding HP, Novoa I, Zhang Y, Zeng H, Wek R, Schapira M, Ron D (2000a) Regulated translation initiation controls stress-induced gene expression in mammalian cells. Mol Cell 6:1099-1108.

Harding HP, Zhang Y, Bertolotti A, Zeng H, Ron D (2000b) Perk is essential for translational regulation and cell survival during the unfolded protein response. Mol Cell 5:897-904.

Harding HP, Zeng H, Zhang Y, Jungries R, Chung P, Plesken H, Sabatini DD, Ron D (2001) Diabetes mellitus and exocrine pancreatic dysfunction in perk $^{-1-}$ mice reveals a role for translational control in secretory cell survival. Mol Cell 7:1153-1163.

Hollien J (2013) Evolution of the unfolded protein response. Biochim Biophys Acta 1833:2458-2463.

Huang G, Yao J, Zeng W, Mizuno Y, Kamm KE, Stull JT, Harding HP, Ron D, Muallem S (2006) ER stress disrupts $\mathrm{Ca}^{2+}$-signaling complexes and $\mathrm{Ca}^{2+}$ regulation in secretory and muscle cells from PERK-knockout mice. J Cell Sci 119:153-161.

Hubbard MJ, Klee CB (1989) Functional domain structure of calcineurin A: mapping by limited proteolysis. Biochemistry 28:1868-1874.

Kao SC, Wu H, Xie J, Chang CP, Ranish JA, Graef IA, Crabtree GR (2009) Calcineurin/NFAT signaling is required for neuregulinregulated Schwann cell differentiation. Science 323:651-654.

Kim HJ, Raphael AR, LaDow ES, McGurk L, Weber RA, Trojanowski JQ, Lee VM, Finkbeiner S, Gitler AD, Bonini NM (2014) Therapeutic modulation of eIF $2 \alpha$ phosphorylation rescues TDP- 43 toxicity in amyotrophic lateral sclerosis disease models. Nat Genet 46:152-160.

Kipanyula MJ, Woodhoo A, Rahman M, Payne D, Jessen KR, Mirsky R (2013) Calcineurin-nuclear factor of activated T cells regulation of Krox20 expression in Schwann cells requires elevation of intracellular cyclic AMP. J Neurosci Res 91:105-115.

Klee CB, Crouch TH, Krinks MH (1979) Calcineurin: a calcium- and calmodulin-binding protein of the nervous system. Proc Natl Acad Sci USA 76:6270-6273.

Kulkens T, Bolhuis PA, Wolterman RA, Kemp S, te Nijenhuis S, Valentijn LJ, Hensels GW, Jennekens FG, de Visser M, Hoogendijk JE (1993) Deletion of the serine 34 codon from the major peripheral myelin protein $\mathrm{P} 0$ gene in Charcot-Marie-Tooth disease type 1B. Nat Genet 5:35-39.

Kuznetsov G, Brostrom MA, Brostrom CO (1992) Demonstration of a calcium requirement for secretory protein processing and export: differential effects of calcium and dithiothreitol. J Biol Chem 267:3932-3939.

Lieberman DN, Mody I (1994) Regulation of NMDA channel function by endogenous $\mathrm{Ca}^{2+}$-dependent phosphatase. Nature 369:235-239.

Lin W, Bailey SL, Ho H, Harding HP, Ron D, Miller SD, Popko B (2007) The integrated stress response prevents demyelination by protecting oligodendrocytes against immune-mediated damage. J Clin Invest 117:448456.

Lin W, Popko B (2009) Endoplasmic reticulum stress in disorders of myelinating cells. Nat Neurosci 12:379-385.

Lin W, Stone S (2020) Unfolded protein response in myelin disorders. Neural Regen Res 15:636-645.

Liu Z, Cai H, Zhu H, Toque H, Zhao N, Qiu C, Guan G, Dang Y, Wang J (2014) Protein kinase RNA-like endoplasmic reticulum kinase (PERK)/ calcineurin signaling is a novel pathway regulating intracellular calcium accumulation which might be involved in ventricular arrhythmias in diabetic cardiomyopathy. Cell Signal 26:2591-2600.

Liu Z, Lv Y, Zhao N, Guan G, Wang J (2015) Protein kinase R-like ER kinase and its role in endoplasmic reticulum stress-decided cell fate. Cell Death Dis 6:e1822.

Luo J, Sun L, Lin X, Liu G, Yu J, Parisiadou L, Xie C, Ding J, Cai H (2014) A calcineurin- and NFAT-dependent pathway is involved in $\alpha$-synucleininduced degeneration of midbrain dopaminergic neurons. Hum Mol Genet 23:6567-6574.

Madsen K, Reddy RN, Price SR, Williams CR, Gooch JL (2013) Nutritional intervention restores muscle but not kidney phenotypes in adult calcineurin A $\alpha$ null mice. PLoS One 8:e62503.

Martina JA, Puertollano R (2018) Protein phosphatase 2A stimulates activation of TFEB and TFE3 transcription factors in response to oxidative stress. J Biol Chem 293:12525-12534.

Medina DL, Di Paola S, Peluso I, Armani A, De Stefani D, Venditti R, Montefusco S, Scotto-Rosato A, Prezioso C, Forrester A, Settembre C,
Wang W, Gao Q, Xu H, Sandri M, Rizzuto R, De Matteis MA, Ballabio A (2015) Lysosomal calcium signalling regulates autophagy through calcineurin and TFEB. Nat Cell Biol 17:288-299.

Mehta S, Aye-Han NN, Ganesan A, Oldach L, Gorshkov K, Zhang J (2014) Calmodulin-controlled spatial decoding of oscillatory $\mathrm{Ca}^{2+}$ signals by calcineurin. Elife 3:e03765.

Mekahli D, Bultynck G, Parys JB, Smedt HD, Missiaen L (2011) Endoplasmic-reticulum calcium depletion and disease. Cold Spring Harb Perspect Biol 3:a004317.

Miller LJ, Patzko A, Lewis RA, Shy ME (2012) Phenotypic presentation of the Ser63Del MPZ mutation. J Peripher Nerv Syst 17:197-200.

Moreno JA, Halliday M, Molloy C, Radford H, Verity N, Axten JM, Ortori CA, Willis AE, Fischer PM, Barrett DA, Mallucci GR (2013) Oral treatment targeting the unfolded protein response prevents neurodegeneration and clinical disease in prion-infected mice. Sci Transl Med 5:206ra138.

Mukherjee A, Soto C (2011) Role of calcineurin in neurodegeneration produced by misfolded proteins and endoplasmic reticulum stress. Curr Opin Cell Biol 23:223-230.

Mukherjee A, Morales-Scheihing D, Gonzalez-Romero D, Green K, Taglialatela G, Soto C (2010) Calcineurin inhibition at the clinical phase of prion disease reduces neurodegeneration, improves behavioral alterations and increases animal survival. PLoS Pathog 6:e1001138.

Muñoz JP, Ivanova S, Sánchez-Wandelmer J, Martínez-Cristóbal P, Noguera E, Sancho A, Díaz-Ramos A, Hernández-Alvarez MI, Sebastián D, Mauvezin C, Palacín M, Zorzano A (2013) Mfn2 modulates the UPR and mitochondrial function via repression of PERK. EMBO J 32:2348-2361.

Musner N, Sidoli M, Zambroni D, Del Carro U, Ungaro D, D'Antonio M, Feltri ML, Wrabetz L (2016) Perk ablation ameliorates myelination in S63del-Charcot-Marie-Tooth 1B neuropathy. ASN Neuro 8:175909141664235.

Neilson JR, Winslow MM, Hur EM, Crabtree GR (2004) Calcineurin B1 is essential for positive but not negative selection during thymocyte development. Immunity 20:255-266.

Novoa I, Zeng H, Harding HP, Ron D (2001) Feedback inhibition of the unfolded protein response by GADD34-mediated dephosphorylation of eIF2 $\alpha$. J Cell Biol 153:1011-1022.

Paez PM, Spreuer V, Handley V, Feng JM, Campagnoni C, Campagnoni AT (2007) Increased expression of Golli myelin basic proteins enhances calcium influx into oligodendroglial cells. J Neurosci 27:12690-12699.

Pennuto M, Tinelli E, Malaguti M, Del Carro U, D’Antonio M, Ron D, Quattrini A, Feltri ML, Wrabetz L (2008) Ablation of the UPR-mediator $\mathrm{CHOP}$ restores motor function and reduces demyelination in CharcotMarie-Tooth 1B mice. Neuron 57:393-405.

Prell T, Lautenschläger J, Grosskreutz J (2013) Calcium-dependent protein folding in amyotrophic lateral sclerosis. Cell Calcium 54:132-143.

Proud CG (2001) Regulation of eukaryotic initiation factor eIF2B. In: Signaling pathways for translation: insulin and nutrients: progress in molecular and subcellular biology (Rhoads RE, ed), pp 95-114. Berlin: Springer.

Quattrini A, Previtali S, Feltri ML, Canal N, Nemni R, Wrabetz L (1996) Beta 4 integrin and other Schwann cell markers in axonal neuropathy. Glia 17:294-306.

Radford H, Moreno JA, Verity N, Halliday M, Mallucci GR (2015) PERK inhibition prevents tau-mediated neurodegeneration in a mouse model of frontotemporal dementia. Acta Neuropathol 130:633-642.

Reddy RN, Pena JA, Roberts BR, Williams SR, Price SR, Gooch JL (2011) Rescue of calcineurin $\mathrm{A} \alpha^{-1-}$ mice reveals a novel role for the $\alpha$ isoform in the salivary gland. Am J Pathol 178:1605-1613.

Reed CB, Frick LR, Weaver A, Sidoli M, Schlant E, Feltri ML, Wrabetz L (2020) Deletion of calcineurin in Schwann cells does not affect developmental myelination, but reduces autophagy and delays myelin clearance after peripheral nerve injury. J Neurosci 40:6165-6176.

Rumi-Masante J, Rusinga FI, Lester TE, Dunlap TB, Williams TD, Dunker AK, Weis DD, Creamer TP (2012) Structural basis for activation of calcineurin by calmodulin. J Mol Biol 415:307-317.

Rusnak F, Mertz P (2000) Calcineurin: form and function. Physiol Rev 80:1483-1521

Saito A, Ochiai K, Kondo S, Tsumagari K, Murakami T, Cavener DR, Imaizumi K (2011) Endoplasmic reticulum stress response mediated by the PERK-eIF2 $\alpha$-ATF4 pathway is involved in osteoblast differentiation induced by BMP2. J Biol Chem 286:4809-4818. 
Scapin C, Ferri C, Pettinato E, Bianchi F, Del Carro U, Feltri ML, Kaufman RJ, Wrabetz L, D'Antonio M (2020) Phosphorylation of eIF2 $\alpha$ promotes Schwann cell differentiation and myelination in CMT1B mice with activated UPR. J Neurosci 40:8174-8187.

Scheuner D, Song B, McEwen E, Liu C, Laybutt R, Gillespie P, Saunders T, Bonner-Weir S, Kaufman RJ (2001) Translational control is required for the unfolded protein response and in vivo glucose homeostasis. Mol Cell 7:1165-1176.

Sharma J, Mukherjee D, Rao SN, Iyengar S, Shankar SK, Satishchandra P, Jana NR (2013) Neuronatin-mediated aberrant calcium signaling and endoplasmic reticulum stress underlie neuropathology in Lafora disease. J Biol Chem 288:9482-9490.

Shen X, Li H, Ou Y, Tao W, Dong A, Kong J, Ji C, Yu S (2008) The secondary structure of calcineurin regulatory region and conformational change induced by calcium/calmodulin binding. J Biol Chem 283:11407-11413.

Sherman DL, Brophy PJ (2005) Mechanisms of axon ensheathment and myelin growth. Nat Rev Neurosci 6:683-690.

Shinde V, Kotla P, Strang C, Gorbatyuk M (2016) Unfolded protein response-induced dysregulation of calcium homeostasis promotes retinal degeneration in rat models of autosomal dominant retinitis pigmentosa. Cell Death Dis 7:e2085.

Sidoli M, Musner N, Silvestri N, Ungaro D, D'Antonio M, Cavener DR, Feltri ML, Wrabetz L (2016) Ablation of Perk in Schwann cells improves myelination in the S63del Charcot-Marie-Tooth 1B mouse. J Neurosci 36:11350-11361.

Smith HL, Freeman OJ, Butcher AJ, Holmqvist S, Humoud I, Schätzl T, Hughes DT, Verity NC, Swinden DP, Hayes J, de Weerd L, Rowitch DH, Franklin RJ, Mallucci GR (2020) Astrocyte unfolded protein response induces a specific reactivity state that causes non-cell-autonomous neuronal degeneration. Neuron 105:855-866.e25.

Stevens B, Fields RD (2000) Response of Schwann cells to action potentials in development. Science 287:2267-2271.

Stevens B, Ishibashi T, Chen JF, Fields RD (2004) Adenosine: an activity-dependent axonal signal regulating MAP kinase and proliferation in developing Schwann cells. Neuron Glia Biol 1:23-34.

Taveggia C, Zanazzi G, Petrylak A, Yano H, Rosenbluth J, Einheber S, Xu X, Esper RM, Loeb JA, Shrager P, Chao MV, Falls DL, Role L, Salzer JL (2005) Neuregulin-1 type III determines the ensheathment fate of axons. Neuron 47:681-694

Tong G, Shepherd D, Jahr CE (1995) Synaptic desensitization of NMDA receptors by calcineurin. Science 267:1510-1512.

Topilko P, Schneider-Maunoury S, Levi G, Baron-Van Evercooren A, Chennoufi AB, Seitanidou T, Babinet C, Charnay P (1994) Krox-20 controls myelination in the peripheral nervous system. Nature 371:796-799.

Vervliet T, Kiviluoto S, Bultynck G (2012) ER stress and UPR through dysregulated $\mathrm{ER} \mathrm{Ca}^{2+}$ homeostasis and signaling. In: Endoplasmic reticulum stress in health and disease (Agostinis P, Afshin S, eds), pp 107-142. Dordrecht, The Netherlands: Springer.

van Vliet AR, Giordano F, Gerlo S, Segura I, Van Eygen S, Molenberghs G, Rocha S, Houcine A, Derua R, Verfaillie T, Vangindertael J, De
Keersmaecker H, Waelkens E, Tavernier J, Hofkens J, Annaert W, Carmeliet P, Samali A, Mizuno H, Agostinis P (2017) The ER stress sensor PERK coordinates ER-plasma membrane contact site formation through interaction with filamin-A and F-actin remodeling. Mol Cell 65:885-899.e6.

Wang H, Du Y, Xiang B, Lin W, Li X, Wei Q (2008) A renewed model of $\mathrm{CNA}$ regulation involving its $\mathrm{C}$-terminal regulatory domain and CaM. Biochemistry 47:4461-4468.

Wang R, McGrath BC, Kopp RF, Roe MW, Tang X, Chen G, Cavener DR (2013) Insulin secretion and $\mathrm{Ca}^{2+}$ dynamics in $\beta$-cells are regulated by PERK (EIF2AK3) in concert with calcineurin. J Biol Chem 288:3382433836.

Wei J, Sheng X, Feng D, McGrath B, Cavener DR (2008) PERK is essential for neonatal skeletal development to regulate osteoblast proliferation and differentiation. J Cell Physiol 217:693-707.

Weider M, Starost LJ, Groll K, Küspert M, Sock E, Wedel M, Fröb F, Schmitt C, Baroti T, Hartwig AC, Hillgärtner S, Piefke S, Fadler T, Ehrlich M, Ehlert C, Stehling M, Albrecht S, Jabali A, Schöler HR, Winkler J, et al. (2018) Nfat/calcineurin signaling promotes oligodendrocyte differentiation and myelination by transcription factor network tuning. Nat Commun 9:16.

Wek RC, Cavener DR (2007) Translational control and the unfolded protein response. Antioxid Redox Signal 9:2357-2371.

Wrabetz L, Feltri ML, Quattrini A, Imperiale D, Previtali S, D’Antonio M, Martini R, Yin X, Trapp BD, Zhou L, Chiu SY, Messing A (2000) P0 glycoprotein overexpression causes congenital hypomyelination of peripheral nerves. J Cell Biol 148:1021-1034.

Wrabetz L, D’Antonio M, Pennuto M, Dati G, Tinelli E, Fratta P, Previtali S, Imperiale D, Zielasek J, Toyka K, Avila RL, Kirschner DA, Messing A, Feltri ML, Quattrini A (2006) Different intracellular pathomechanisms produce diverse Myelin Protein Zero neuropathies in transgenic mice. J Neurosci 26:2358-2368.

Wu H, Peisley A, Graef IA, Crabtree GR (2007) NFAT signaling and the invention of vertebrates. Trends Cell Biol 17:251-260.

Wu H, Hudry E, Hashimoto T, Kuchibhotla K, Rozkalne A, Fan Z, SpiresJones T, Xie H, Arbel-Ornath M, Grosskreutz CL, Bacskai BJ, Hyman BT (2010) Amyloid $\beta$ induces the morphological neurodegenerative triad of spine loss, dendritic simplification, and neuritic dystrophies through calcineurin activation. J Neurosci 30:2636-2649.

Yang SA, Klee CB (2000) Low affinity $\mathrm{Ca}^{2+}$-binding sites of calcineurin B mediate conformational changes in calcineurin A. Biochemistry 39:16147-16154.

Zhang BW, Zimmer G, Chen J, Ladd D, Li E, Alt FW, Wiederrecht G, Cryan J, O’Neill EA, Seidman CE, Abbas AK, Seidman JG (1996) T cell responses in calcineurin A alpha-deficient mice. J Exp Med 183:413-420.

Zhang P, McGrath B, Li S, Frank A, Zambito F, Reinert J, Gannon M, Ma K, McNaughton K, Cavener DR (2002) The PERK eukaryotic initiation factor 2 alpha kinase is required for the development of the skeletal system, postnatal growth, and the function and viability of the pancreas. Mol Cell Biol 22:3864-3874. 